\title{
LA CONSTRUCCIÓN DE LA IDENTIDAD P'URHEPECHA A PARTIR DE LA EDUCACIÓN INTERCULTURAL BILINGÜE PROPIA
}

\author{
P'URHEPECHA IDENTITY CONSTRUCTION FROM \\ THEIR OWN INTERCULTURAL BILINGUAL EDUCATION \\ PERSPECTIVE
}

\author{
Rainer Enrique Hamel ${ }^{*}$ \\ Ana Elena Erape Baltazar* \\ Betzabé Márquez Escamilla***
}

\section{RESUMEN}

El proyecto "T'arhexperakua - Creciendo juntos" surge en dos escuelas p'urhepechas de la Meseta Tarasca en el centro-oeste mexicano como iniciativa de un equipo de maestras y maestros indígenas en 1995. Dada la alta vitalidad etnolingüística en la zona, los niños llegan prácticamente monolingües a la escuela. El programa tradicional de "castellanización" había arrojado pésimos resultados, como en las demás escuelas de la región. Los docentes se convencieron a través de su práctica que, en las condiciones imperantes, no era posible enseñar las matemáticas, la lectura y escritura, junto con las demás asignaturas, en una lengua que sus alumnos no conocían. A diferencia de otras escuelas, sin embargo, transformaron su experiencia en acción de cambio. Tomaron la decisión audaz de enseñar todas las asignaturas en p'urhepecha para que los alumnos entendieran bien lo que aprendían, para que lo aprendieran mejor y con mayor participación. En 1999 llegó un equipo de investigación para conocer el proyecto. Por invitación del colegiado docente indígena, realizó un estudio sobre el proyecto escolar y continuó después a desarrollar una larga colaboración con las escuelas en la elaboración de un modelo escolar propio. El presente texto describe el currículo y sus componentes, como también el proceso de planificación curricular. Toma como ejemplo dos clases para demostrar su funcionamiento; una clase en p'urhepecha tematiza la cosmovisión de su territorio, el cerro y sus bosques, y de la defensa del territorio ancestral. La otra clase en p'urhepecha activa su rica morfología con sus clasificadores de forma y tamaño para enseñar la fracción en una clase de matemáticas. La observación de clase muestra de qué

\footnotetext{
*Universidad Autónoma Metropolitana, Depto. de Antropologia, Ciudad de México, México. hamel@xanum.uam.mx

** Universidad Autónoma Metropolitana, Depto. de Antropologia, Ciudad de México, México. anaelenaerape@gmail.com

*** Universidad Autónoma Metropolitana, Depto. de Antropologia, Ciudad de México, México. betzabe.marquez@gmail.com
} 
manera los docentes desarrollan una política lingüística e identitaria en torno a la presencia y funcionalidad de su lengua en el lugar de prestigio que es la escuela.

Palabras clave: identidad p'urhepecha; educación intercultural bilingüe en Mexico; planificación curricular.

\section{SUMMARY}

The "T'arhexperakua - Growing Together" Project emerges in two P'urhepecha primary schools in the centre-west of Mexico's highlands as an initiative of their indigenous teachers. Due to the high ethnolinguistic vitality, pupils enter school as monolinguals. The common approach to teach nevertheless in Spanish only had yielded widespread school failure. Therefore, the teachers started to teach all content matters including maths, language and literacy in the native language to improve learning in 1995. In 1999 a small team of linguists, educationalists and anthropologists were invited by the schools to implement a study of the project. Subsequently, they engaged in a long-lasting collaboration to improve teaching and to develop an intercultural and bilingual curriculum that persists till today. This article reports on the curriculum development and its practice. It analyses two classes carried out entirely in the native language. The first one deals with the indigenous worldview of the concept of territory and the obligation of its defence. The second class mobilises the rich morphological system of P'urhepecha with its classifiers of size and shape to help learn how mathematical fractions work. Our classroom analysis shows in which way teaches develop a language and education policy that fosters linguistic and ethnic identity through the functionally successful use of P'urhepecha in the high prestige school environment.

Keywords: P'urhepecha identity; Intercultural Bilingual Education in Mexico; curricular development.

\section{INTRODUCCIÓN}

Jimani inde jindeesti juchari ich'eri anchintasïnka. komunali, eska mentku iaminducheeriska...ah! aberi xeje iasï.

Entonces eso es nuestro territorio trabajamos nuestra tierra comunal que es de todos.

(Maestro p'urhepecha que explica el concepto de juchari ich'eri - nuestro territorio a sus alumnos)

El proyecto escolar "T'arhexperakua - Creciendo Juntos" se construye frente a una historia de políticas indigenistas, educativas y lingüísticas en México en las que predominó desde siempre una línea que veía en la desaparición de los pueblos indígenas una condición previa para la construcción del estado nacional unificado. Esta fomentó la integración a través de la asimilación de los pueblos indígenas a la cultura nacional, indígenas cuya marginación se definió desde siempre como atraso e incomunicación lingüística, debido supuestamente a su falta de conocimientos de la lengua y cultura nacional. 
A esta línea le correspondió en la educación y enseñanza del español que constituyó desde siempre el pilar fundamental de la política lingüística y cultural dirigida hacia los indígenas $(\mathrm{HEATH}, 1972)$ - una castellanización directa (programas de sumersión, en términos modernos) o la asimilación indirecta a través de diversos métodos bilingües, donde a la lengua indígena le correspondía un papel instrumental de apoyo en la enseñanza (programas de transición); en algunos casos se proponía una alfabetización rudimentaria en la lengua vernácula (HAMEL, 2016).

En los primeros decenios del siglo XX, destacados antropólogos como Manuel Gamio consideraban que la incorporación del indio a la sociedad mestiza era necesaria para «caracterizar a la población mexicana para que ésta constituya y encarne una patria poderosa y una nacionalidad coherente y definida» (GAMIO, 1916/1992: 183). González Apodaca (2008: 35) menciona que la escolarización tuvo un papel central en la perspectiva de incorporación de Gamio «en tanto herramienta central del cambio cultural inducido» que debía trascender las funciones alfabetizadoras y castellanizadoras, para convertirse en una educación integral con criterio nacionalista y bases científicas.

Frente a estas políticas de asimilación, los pueblos indígenas y otros agentes políticos impulsaron movimientos con reivindicaciones educativas que iban desde el acceso a la educación hasta el reclamo de crear un sistema propio, basado en las culturas y lenguas indígenas y bajo su control. Por otro lado, con la globalización, surgieron exigencias de transformaciones profundas de los Estados latinoamericanos que incluían reformas educativas para lograr una mayor eficiencia de sus sistemas como condición para el desarrollo. En estas innovaciones, la educación indígena juega un papel complejo y controvertido (HAMEL, 2001).

Sin duda existen avances en la formulación de programas y proyectos basados en el concepto de educación intercultural bilingïe, generalizado desde los años 1990 en América Latina (LÓPEZ, 2009). En México la educación indígena (tres años de preescolar y seis de primaria) es organizada desde el gobierno federal a través de la Dirección General de Educación Indígena (DGEI), donde unos 55 mil maestras y maestros indígenas bilingües atienden a 1,25 millones de alumnos (el 50\% del total de alumnos indígenas de pre- y primaria en el país). A pesar de este aparato impresionante por sus cifras, México es al mismo tiempo quizás la única república federativa con más de 100 millones de habitantes en el mundo que mantiene vigente un currículo único y obligatorio para toda la población escolar de preprimaria y primaria, incluyendo la población indígena, lo que ha contribuido a que el subsistema de educación indígena exhiba los peores resultados de todos los niveles de educación pública (INEE, 2008, INEE-UNICEF, 2016). 


\section{EL PROYECTO ESCOLAR T'ARHEXPERAKUA - CRECIENDO JUNTOS EN MICHOACÁN, MÉXICO}

Es en este contexto que el cuerpo docente de las escuelas p'urhepechas de San Isidro y Uringuitiro comenzó en 1995/96 un proyecto escolar propio de gran alcance. Debido a la alta vitalidad lingüística en la región, sus alumnos llegaban prácticamente monolingües en lengua indígena a la escuela. El programa tradicional de "castellanización" había arrojado pésimos resultados, como en las demás escuelas de la región. Los docentes se convencieron a través de su práctica que, en las condiciones imperantes, no era posible enseñar las matemáticas, la lectura y escritura, junto con las demás asignaturas, en una lengua que sus alumnos no conocían. A diferencia de otras escuelas, sin embargo, transformaron su experiencia en acción de cambio y no siguieron con las rutinas indeseables pero establecidas. Tomaron la decisión audaz y a la vez correcta de enseñar todas las asignaturas en p'urhepecha para que los alumnos entendieran bien lo que aprendían, para que lo aprendieran mejor y con mayor participación. Y no se cuestionaba el hecho que tenían que basar sus cambios en el currículo nacional, por lo menos en un inicio.

Durante los primeros años había que crearlo todo: definir un alfabeto en p'urhepecha, desarrollar una metodología para la alfabetización en lengua materna y elaborar materiales para todas las materias (ALONSO et al, 2004). Quizás lo más difícil para los maestros y maestras p'urhepechas formados en un sistema castellanizador fue tomarle confianza a su propia lengua, aprender a usarla en el aula con precisión y, por qué no, con orgullo y alegría, aprender a leer y escribir en ella para poder enseñarle la lectura y escritura a los niños. Así, el p'urhepecha llegó a ser la lengua legítima y normal de prácticamente todas las interacciones escolares entre alumnos, maestros y padres de familia. No tuvo que pedir permiso para entrar, como en tantas otras escuelas, y nadie discriminaba a los niños porque utilizaban con mucha naturalidad su lengua materna durante las clases y el recreo. En la concepción de los maestros, la lengua p'urhepecha ocupa el lugar central en su currículo y determina todas las demás materias.

Conocimos las escuelas p'urhepechas en 1998, cuando en un equipo de investigadores recorrimos varios estados de la república. Buscábamos escuelas indígenas exitosas, con un proyecto escolar propio, que ofrecieran una práctica más adecuada a las necesidades y aspiraciones de los alumnos indígenas y sus comunidades. Cuando nos asomamos a las aulas y empezamos a conversar con los maestros, nos entusiasmamos de inmediato y nos dimos cuenta que estábamos frente a un proyecto escolar excepcional: Aquí los fundadores del proyecto habían formado un equipo, analizaron la situación y tomaron decisiones de cambio para 
luego ponerlas en práctica. No esperaron que algún día, desde arriba, desde algún lugar remoto del sistema de educación indígena, les llegaran las soluciones adecuadas - seguramente las estarían esperando hasta el día de hoy. Con gran generosidad los maestros y autoridades nos invitaron a quedarnos a conocer y estudiar su proyecto escolar y a ayudar a mejorarlo.

A partir de ese momento iniciamos un largo trabajo colaborativo de investigación, intervención y desarrollo escolar que integró la planta docente y el equipo externo de investigadores. La investigación colectiva se constituyó posteriormente como programa permanente de investigación y asesoría con el nombre de «Comunidades indígenas y educación intercultural bilingüe (CIEIB)», con sede en el Departamento de Antropología de la UAM-Iztapalapa. Muchos años después, los docentes p'urhepechas escogieron el nombre de «T'arhexperakua Creciendo juntos» para su proyecto escolar que incluye la colaboración externa. Y desde entonces, la colaboración continúa a finales de 2018, cuando escribimos este artículo.

\section{LA POLÍTICA DE IDENTIDAD ÉTNICA DE LOS PROFESORES P'URHEPECHAS: HISTORIA PROPIA Y PROYECTO ESCOLAR}

¿En qué sentido podemos entender la iniciativa de maestras y maestros como una política y, de hecho, una planificación que desafía el sistema educativo asimilacionista y construye una identidad p'urhepecha propia?

Un estudio realizado en un estado avanzado de nuestra colaboración (2011) revela motivaciones y orientaciones muy profundas enraizadas en las biografías escolares y lingüísticas de los docentes, todos ellos p'urhepechas, para emprender su proeza de buscar construir un proyecto educativo propio que les ofrezca condiciones más adecuadas y felices de educación intercultural bilingüe sus alumnos de las que ellos mismos tuvieron'.

Llama la atención que todas y todos los entrevistados colocaron el tema de las lenguas en el centro de su construcción biográfica, aun cuando se les solicitó más bien un relato sobre su trayectoria educativa. Algunos iniciaron su vida como monolingües en p'urhepecha, otros en español. Ninguno de ellos alcanzó a desarrollar un bilingüismo satisfactorio en su niñez y en la escuela primaria indígena,

1. Este estudio fue propuesto y encabezado por Ana Carolina Hecht, especialista argentina en educación indígena e investigadora del CONICET, quien pasó una estancia de posdoctorado en nuestro proyecto en 2011. Ver Hamel, Hecht, Erape Baltazar y Márquez Escamilla (2018) de donde extraemos algunos resultados para el presente texto. 
cuya función y tarea principal debería ser, justamente, alcanzar ese objetivo. Por el contrario, recuerdan su paso por la primaria como un proceso traumático, sobre todo aquellos que eran monolingües en lengua indígena. Ambos grupos adquirieron un bilingüismo tardío, muchas veces recién en la educación secundaria, en su formación como maestros (Escuela Normal o Universidad Pedagógica) o en el ejercicio de la profesión.

A pesar de la asimetría diglósica que opera entre las dos lenguas, no sólo los que aprendieron el español, sino también los que adquirieron el p'urhepecha como segunda lengua (L2), sintieron la necesidad de aprender la otra lengua para poder comunicarse y construir su identidad plena, lo que le otorga, en sus orientaciones y actitudes, una gran legitimidad al sistema de comunicación p'urhepecha bilingüe. No cabe duda que, para ellos, la lengua propia, como el bilingüismo mismo, se ubican entre los valores nucleares (SMOLICZ, 1981, 1994) de la identidad étnica de las comunidades p'urhepechas donde viven y trabajan. La lengua propia constituye el núcleo de la cultura p'urhe. Explica por qué colocaron la lengua p'urhepecha en el centro de las materias y competencias escolares en su diseño curricular, como veremos más adelante. Sin duda, su trabajo reflexivo sobre su situación lingüística (MUÑNZ CRUZ, 2009) juega un papel importante en la identificación con su proyecto escolar.

En la interpretación retrospectiva de sus biografías a partir del aquí y ahora, los docentes establecen una clara dicotomía, un contraste entre su propia escolaridad traumática y el deseo de construirles una alternativa mejor a sus alumnos. En sus orientaciones se combinan dos componentes. Por un lado, el p'urhepecha preserva una innegable vitalidad etnolingüística, funcionalidad comunicativa y un prestigio en la región. Constituye un polo lo suficientemente atractivo para que los docentes indígenas hispanohablante aprendan la lengua como L2, aunque sea en forma tardía e incompleta. En caso de que ocurra un proceso de desplazamiento acelerado en un futuro próximo, es probable que la lengua indígena pierda su atractivo y que los estudiantes en formación pedagógica, como también los docentes en servicio, ya no inviertan tiempo y esfuerzo en su aprendizaje. Esto ocurre en una gran parte de las regiones indígenas en México, donde el requisito otrora indispensable de ser bilingüe para ingresar a la carrera docente indígena se diluye cada vez más (HAMEL, 2010).

Por otro lado, la conciencia de ser parte de un proyecto escolar propio bastante reconocido constituye, sin duda, un momento unificador y orientador en las experiencias biográficas individuales y divergentes; establece una diferencia con muchos otros docentes que no participan en un proyecto escolar propio y 
no perciben su práctica profesional como destacada o particularmente pertinente. Muchos maestros y maestras indígenas pasaron por procesos educativos muy similares, igualmente traumáticos y con resultados deficientes. A falta de un proyecto colectivo como alternativa profesional, optan por líneas de acción y por orientaciones opuestas; abandonan la lengua y cultura indígenas, tanto en su desempeño profesional como en la socialización de sus descendientes. Castellanizan y enseñan exclusiva o predominantemente en español, aun cuando esta práctica, comprobada como inapropiada, lleve a resultados poco satisfactorios y reproduzca de algún modo las propias experiencias traumáticas en sus alumnos.

El proyecto escolar T'arhexperakua, como veremos más adelante, constituye un foco de fortalecimiento y revitalización de la lengua y cultura indígenas. La experiencia colectiva y el uso eficiente del p'urhepecha en este espacio de prestigio ejerce una presión muy significativa sobre aquellos ciudadanos p'urhepechas, en particular los docentes, que están en un proceso de abandono personal de la lengua indígena o sobre quienes la hablan poco y dudan si vale la pena el esfuerzo de fortalecerla.

En el contexto de un debate bastante reciente, no solo en México sino en América Latina en su conjunto, acaso el dominio de la lengua indígena constituye un valor nuclear de la identidad étnica, el ejemplo de T'arhexperakua constituye una respuesta sin ambages: sin la lengua se pierde la identidad étnica; o como lo dicen los guaraníes Mbya en el suroeste brasileño: si perdemos nuestra lengua, perdemos nuestro territorio (MENDONÇA, 2018).

Los docentes del proyecto T'arhexperakua se identifican positivamente con sus alumnos como miembros del mismo pueblo p'urhepecha y optan por darles una educación de mejor calidad. Esta orientación se expresa en una práctica docente y en un currículo intercultural bilingüe que coloca en el centro del quehacer escolar la propia lengua y los conocimientos vigentes en su cultura, cuyo valor reconocieron y asumieron recién en su formación docente y el ejercicio de su profesión. Construyen de esta manera una fuerte identidad colectiva que lleva al empoderamiento de ellos mismos, de sus alumnos, de las comunidades y de un proyecto escolar que reconocen como propio. Así lo expresa un maestro:

Yo les digo a mis compañeros, bueno, el compromiso es mayor de nosotros...

si, si este... porque si nosotros siendo parte, no les damos... una buena educación a nuestros niños, que son nuestros hermanos, vean que son nuestros hermanos, la raza, no creo que venga otra gente, les digo (...) Nosotros somos, nosotros somos los principales protagonistas de que se dé una buena educación con nuestros hermanos de raza" (Maestro, 39 años). 


\section{LA CONSTRUCCIÓN DE UN CURRÍCULO INTERCULTURAL BILINGÜE COMO EXPRESIÓN DE UNA POLÍTICA DE IDENTIDAD AUTO-AFIRMATIVA}

Estas orientaciones llevaron a los docentes a emprender un largo camino de transformación de su diseño curricular. En un inicio, las razones que expresaban los maestros para enseñar todo el currículo en p'urhepecha fueron más bien defensivas. Argumentaban, con razón, que sus alumnos no hablaban todavía el español, de modo que no podían usarlo como principal instrumento de la enseñanza. El cambio de orientación, que se reflejan en sus entrevistas biográficas, llevó varios años. Fue tan sólo cuando se estableció una buena rutina y cierta seguridad entre los maestros en la docencia en su propia lengua que las explicaciones y justificaciones de su proyecto se volvieron más afirmativas; y también surgió, finalmente, el interés por incluir contenidos, temas y expresiones de la propia cultura y cosmovisión en el currículo, para que la práctica escolar contribuyera no sólo a la preservación y la extensión de la lengua propia, sino también a la protección y revitalización del conjunto de prácticas culturales ancestrales de las comunidades.

\subsection{Los inicios: ajuste curricular y programa de español L2}

En un inicio, pensábamos que era suficiente realizar un ajuste del currículo oficial, mejorar las prácticas de enseñanza en lengua indígena y, como primera innovación, elaborar un Programa de Español L2, que la Secretaría de Educación Pública (SEP) federal nunca quiso producir.

Pero poco a poco nos dimos cuenta que no tenía sentido producir algunos parches y ajustes. Fue necesario construir un currículo completo de EIB que integrara el currículo oficial, pero que lo subvirtiera en su ideología monocultural, creando todos los instrumentos curriculares adicionales propios. En un largo proceso de varios años identificamos las necesidades y nos pusimos entre todos a elaborar las soluciones.

\subsection{El currículo intercultural bilingüe}

Los instrumentos curriculares y el enfoque de la educación intercultural bilingüe p'urhepecha se basan en tres principios lingüísticos que surgieron de las buenas prácticas en el aula, de una sistematización de los enfoques implícitos y de las teorías que sustentan el proyecto escolar (HAMEL, 2010):

1. La lengua propia forma el núcleo, el punto de partida y el principal instrumento para ingresar a la sociedad del conocimiento p'urbepecha, nacional e internacional. 
2. Las dos lenguas constituyen a la vez contenidos curriculares, es decir, lenguas de estudio y también lenguas de instrucción.

3. La enseñanza-aprendizaje se desarrolla a través del enfoque del Aprendizaje Integrado de Contenidos y Lenguas (AICL).

Una de las mayores innovaciones del currículo EIB p'urhe consiste en su nueva conceptualización de la relación entre las lenguas y las asignaturas temáticas como desarrollo integrado y recíproco. Este enfoque ya estaba enunciado en Plan y Programas (1993: 21 -27) de la Secretaría de Educación Pública (SEP) mexicana para la relación entre las asignaturas y el español. Nuestro currículo actualiza, explicita y en cierto modo radicaliza los conceptos y los define para la EIB en general. Se trata de una concepción que hasta la fecha cuenta con poco desarrollo en los programas y currículos de EIB que conocemos de otros países latinoamericanos (COYLE, 2007).

Cuadro 1: La integración de contenidos y lenguas (AICL)

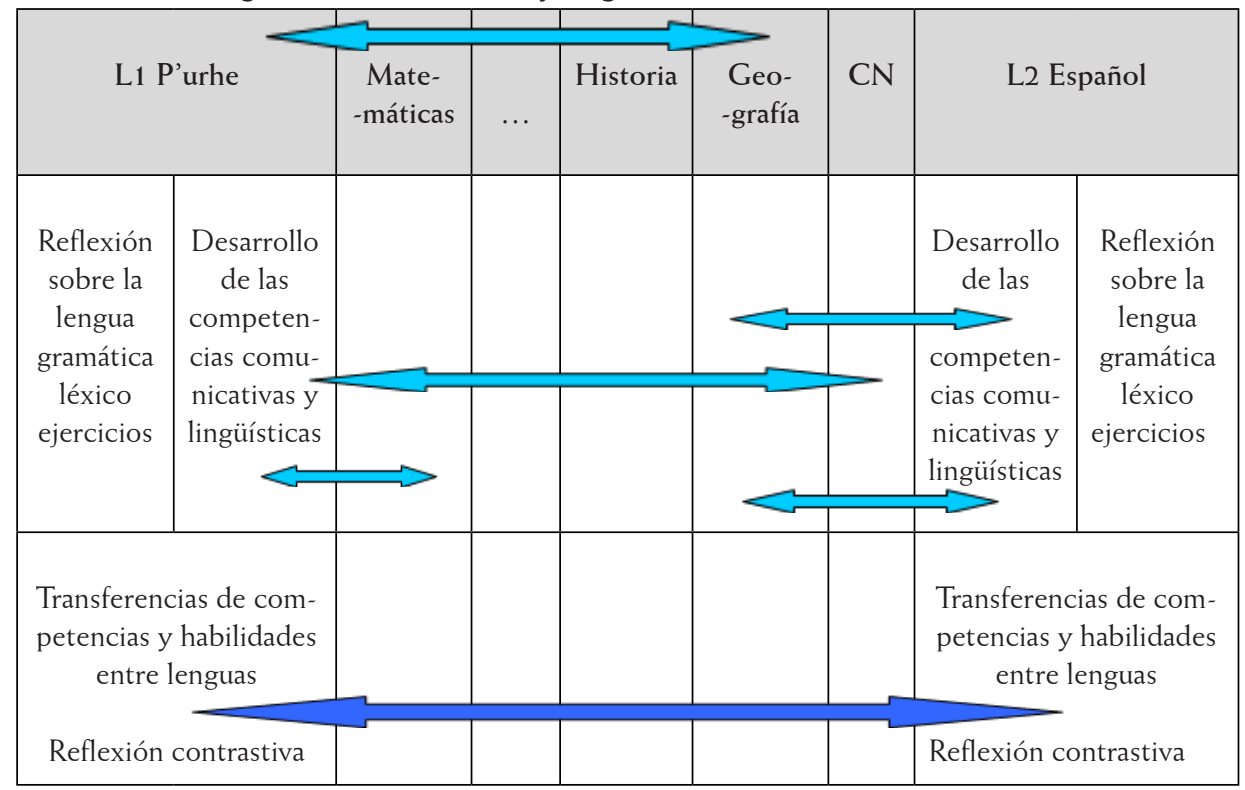

Tradicionalmente las lenguas se han concebido como una asignatura más, desligada de otras materias (español, lengua indígena, lengua extranjera), una práctica desarrollada en muchas partes del mundo. La investigación, sobre todo en contextos de educación bilingüe, ha mostrado, sin embargo, que el aislamiento de la enseñanza de las lenguas produce efectos negativos y lleva muchas veces a 
una enseñanza estéril y centrada en la gramática. Los contenidos de los libros y sus lecciones son aleatorios en relación con las demás asignaturas y se elaboran con el propósito de enseñar y practicar determinados contenidos del lenguaje (vocabulario, gramática, géneros, etc.).

Sabemos, en cambio, que una lengua se aprende mejor cuando se estudia a través de contenidos significativos y atractivos. Cuando esto ocurre, los alumnos desarrollan competencias y habilidades, aprenden estructuras y vocabulario casi sin darse cuenta y, en general, de manera bastante eficaz, impulsados por el deseo de comprender los contenidos (escuchando y leyendo), de expresar sus intenciones, puntos de vista, opiniones y dudas (hablando y escribiendo), como también formular preguntas y solicitudes auténticas. Este enfoque de la "enseñanza de las lenguas basada en contenidos" cuenta hoy con una aceptación prácticamente universal como uno de los métodos más apropiados para la enseñanza y el desarrollo de la lengua materna y la enseñanza de una segunda lengua o lengua extranjera en los más diversos contextos educativos (RICHARD \& RODGERS 2001, HALL HALEY \& AUSTIN 2004, COYLE 2007). Y lo más interesante es que los buenos maestros y maestras indígenas siempre han enseñado así, desde mucho antes de que existiera el término.

\subsection{La planificación de clases}

La planificación de la enseñanza se organiza en tres niveles. En el nivel más abstracto se encuentran tres programas anuales: el Plan y Programa de Estudios IB P'urhepecha y los Programas P'urhepecha L1 y Español L2 que pertenecen al Área de Comunicación y lenguas del currículo. En el nivel 2 se hallan los Planes Bimestrales que integran elementos de los tres programas anteriores y dosifican el programa en cinco bimestres por año escolar. En el nivel más micro se ubican los planes semanales y diarios.

Cuadro 2. Niveles de planificación de clases

$1^{\circ}$ nivel:

\begin{tabular}{|c|c|c|}
\hline $\begin{array}{c}\text { PROGRAMA P'URHEPECHA } \\
\text { L1 }\end{array}$ & $\begin{array}{c}\text { PLAN Y PROGRAMA } \\
\text { DE ESTUDIOS IB } \\
\text { P'urhepecha }\end{array}$ & $\begin{array}{c}\text { PROGRAMA ESPANONOL } \\
\text { L2 }\end{array}$ \\
\hline Competencias, contenidos & $\begin{array}{c}\text { Competencias, contenidos, } \\
\text { indicadores }\end{array}$ & $\begin{array}{c}\text { Competencias, contenidos } \\
\boldsymbol{y}\end{array}$ \\
\hline
\end{tabular}


$2^{\circ}$ nivel.

\begin{tabular}{|c|c|c|c|c|}
\hline \multicolumn{4}{|c|}{ PLAN BIMESTRAL } \\
\hline \multicolumn{4}{|c|}{ COMPETENCIAS, APRENDIZAJES ESPERADOS } \\
\hline $\begin{array}{c}\text { CONTENIDOS INTRA- } \\
\text { CULTURALES E } \\
\text { INTERCULTURALES }\end{array}$ & $\begin{array}{c}\text { Función comu- } \\
\text { nicativa }\end{array}$ & $\begin{array}{c}\text { Concepto y } \\
\text { vocabulario }\end{array}$ & Aspectos & $\begin{array}{c}\text { Lenguaje, } \\
\text { gramática y } \\
\text { vocabulario }\end{array}$ \\
\hline
\end{tabular}

$3^{\circ}$ nivel:

\begin{tabular}{|c|c|c|c|c|}
\hline \multicolumn{4}{|c|}{ PLAN SEMANAL } \\
\hline ¿QUÉ VOY A ENSEÑAR? & \multicolumn{3}{|c|}{ ¿CÓMO LO VAN A APRENDER? } \\
\hline Contenidos & L & Actividades & $\begin{array}{r}\text { Tiempo } \\
(\mathrm{h} / \mathrm{sem})\end{array}$ & Materiales \\
\hline \multicolumn{4}{|c|}{} \\
\hline
\end{tabular}

\section{Plan y Programa de Estudios P Plan y Programa Nacional, P'urhepecha L1 y Español L2}

El programa de estudio para la educación básica de la SEP se compone hoy en día de cuatro campos de formación (a. lenguaje y comunicación; b. pensamiento matemático; c. exploración y comprensión del mundo natural y social ${ }_{;}$d. desarrollo personal y para la convivencia), que a su vez se convierten en asignaturas (español, matemáticas, ciencias naturales, geografía, historia, formación cívica y ética, educación artística y educación física). Cada una tiene su propia organización en cuanto a contenidos, aprendizajes esperados y competencias por bloque o bimestre. En el Plan y Programa de Estudios IB P'urhepecha se integran contenidos y temas culturales de la sociedad p'urhepecha (contenidos intraculturales) y los contenidos del currícula nacional (contenidos interculturales, desde la perspectiva de los alumnos indígenas).

\subsubsection{El Área de Comunicación y Lenguas: L1 y L2}

Esta área contiene los dos Programas de lengua, del p'urhepecha como primera lengua (L1) y del español como segunda lengua $(L 2)^{2}$. Por razones conceptuales y

2. No podemos entrar aquí a la discusión internacional sobre la conceptualización y caracterización de las lenguas en un currículo bilingüe. En algunos contextos, sobre todo urbanos donde existe un cierto equilibro en el dominio de las lenguas y se observan prácticas extendidas de cambio y fusión 
también prácticas, estos programas se han separado del Programa de Asignaturas para poder satisfacer las necesidades de un currículo EIB moderno de acuerdo con las orientaciones actuales a nivel nacional e internacional.

\section{El repertorio comunicativo bilingüe}

Las diferentes lenguas que un sujeto bi- o multilingüe domina o aprende no existen de manera aislada como se pensaba durante mucho tiempo; constituyen más bien un repertorio comunicativo bilingüe integrado donde las lenguas se relacionan de múltiples maneras complejas y pueden cumplir funciones diferenciadas. Se producen, por un lado, interconexiones negativas (interferencias) que se reflejan cuando los alumnos usan estructuras de una lengua de manera inapropiada en la otra o tienen dificultades en la L2 porque posee estructuras o gramaticalizaciones de las cuales su L1 carece (el género y los tiempos verbales, determinado vocabulario, etc.). Estas interferencias ocurren sobre todo en la superficie de las lenguas, es decir, en su estructura gramatical, vocabulario y fonología donde el p’urhepecha y el español difieren radicalmente. Por otro lado, se producen transferencias positivas entre las lenguas. Éstas ocurren sobre todo en las áreas de conocimiento más abstractas que fueron llamadas "proficiencia subyacente común a las lenguas (PSC)" (CUMMINS, $2000)^{3}$; abarcan aquellas habilidades y conocimientos que son compartidos por las dos lenguas: la capacidad general de leer y escribir, el conocimiento de los tipos de texto, el razonamiento lógico-matemático, la abstracción y la generalización. La transferencia entre las lenguas (o el acceso desde cualquiera de las lenguas a la PSC) constituye uno de los instrumentos más poderosos en la organización eficiente de un currículo bilingüe desde una perspectiva del enriquecimiento lingüístico.

de códigos (AUER, 1999), la distinción entre L1 (lengua materna) y L2 pierde sentido. En nuestro caso, sin embargo, la distinción de L1 y L2, que denominamos "lengua más fuerte" y "lengua más débil" desde una perspectiva psicolingüística, mantiene su plena vigencia en términos descriptivos y de política educativa. Funciona como un dispositivo que permite defender y fundamentar el papel de la lengua indígena como L1 en su función de principal lengua de instrucción. Al mismo tiempo, opera como argumento explicativo y defensor de una realidad psico- y sociolingüística frente a expectativas y exigencias irreales de algunos sectores educativos y políticos en cuanto a las posibilidades realistas de alcanzar una proficiencia cuasi-nativa en español L2 en la educación primaria, cuando esta lengua tiene una presencia muy débil en el entorno social de los alumnos.

3. No podemos explicar aquí la teoría de la interdependencia entre lenguas de Cummins (una versión actualizada se encuentra en CUMMINS, 2000). Es importante señalar que esta concepción se sustenta en que existen en el lenguaje diferentes módulos (modular approach, cf. FRANCIS 2002, 2012) como el lenguaje cotidiano con mucha contextualización, frente a discursos académicos o de segundo orden que establecen exigencias cognitivas mayores y funcionan con menor contextualización espacio-temporal. 
El currículo p'urhe procura reducir las interferencias y fomentar al máximo las transferencias positivas.

El programa P'urhepecha L1 sistematiza el desarrollo de las habilidades lingüísticas propias de un tipo de texto oral $\mathrm{y} / \mathrm{o}$ escrito por grado a partir de funciones comunicativas. Además, incorpora siete Unidades Temáticas P’urhepechas ${ }^{4}$, que fueron desarrolladas a partir de campos semánticos donde uno o dos conceptos y sus vocablos dan origen al núcleo central; se ubican típicamente en el centro y le dan unidad al campo mismo, muchas veces como archilexema; es decir, constituyen el concepto central que engloba el campo semántico en su conjunto. De ahí se identifican sub-conceptos que constituyen ejes temáticos transversales, propiciando la construcción de los contenidos culturales con su vocabulario y conceptos propios.

El programa de Español (L2), contiene los contenidos y las competencias de español como segunda lengua para que los alumnos y alumnas indígenas, sobre todo aquellos que son monolingües en lengua indígena o bilingües incipientes al ingresar a la educación primaria, aprendan con eficiencia la lengua mayoritaria, que puedan apropiarse de los contenidos curriculares (ROCKWELL, 2005) también a través de su segunda lengua y que estén en condiciones de cursar con éxito los niveles educativos subsiguientes.

El programa forma parte de la asignatura Lengua que en el currículo nacional monolingüe se llama Español; se combina y se complementa con el Programa de Enseñanza del P'urhepecha (L1) y desarrolla además los componentes necesarios para la enseñanza de una segunda lengua en un currículo bilingüe. Presupone la enseñanza de la lectura y escritura en L1 durante los dos primeros grados y se basa en la posibilidad de transferencias de componentes de la proficiencia lingüística cognitivo-académica de L1 a L2 y viceversa. Por esta razón, no se necesita alfabetizar en español, sino enseñar la especificidad de la lectura y escritura en la L2. Durante los dos primeros grados, se concentra en el desarrollo de las habilidades audio-orales. A partir del tercer grado, desarrolla las cuatro habilidades. El programa establece estándares de dominio para cada grado y procede metodológicamente con un concepto de progresión en el aprendizaje de las formas gramaticales en tres niveles: en el primero los alumnos aprenden las estructuras de manera «formulaica», como formas fijas (« ¿Cómo te llamas?»). En el segundo nivel se desarrolla una capacidad de producción que implica la capacidad de transferencia de determinadas estructuras

4. Hasta 2012 el proyecto elaboró las siguientes unidades: a. sobre el origen y la creación de la vida; b. las plantas y los animales y su relación con la vida humana; c. salud y alimentación del pueblo p'urhepecha; $\mathrm{d}$. el arte, los oficios y los juegos tradicionales; e. ayuda mutua del pueblo p'urhepecha; f. respeto y tolerancia en nuestra cultura; g. organización social y política del pueblo p'urhepecha. 
gramaticales desde los contextos de aprendizaje a nuevos contextos y producen las formas gramaticalmente correctas que exige el contexto. En el tercer nivel, de dominio, los alumnos ya desarrollan la capacidad de corrección y autocorrección y un manejo consciente de ciertas reglas gramaticales fundamentales (EMILSSON, 2010: 8-9).

En ambos programas se estableció un perfil de egreso de la primaria que pretende alcanzar un bilingüismo coordinado, es decir, que los egresados adquieran una competencia comunicativa y académica que integre las cuatro habilidades (escuchar, hablar, leer y escribir) en las dos lenguas y que sepan expresarse adecuadamente en los contextos que le sean familiares. En el caso de alumnos y alumnas que son monolingües al ingresar al preescolar o la primaria y que tienen poco contacto con el español en su vida extraescolar, no se pretende alcanzar un bilingüismo equilibrado al concluir la educación primaria, ya que un tal nivel no es alcanzable en las condiciones sociolingüísticas descritas.

\section{Planes bimestrales $\Rightarrow$ Articulan competencias y contenidos de los programas de estudio}

Los planes bimestrales constituyen el principal instrumento para la planeación y desarrollo de las actividades de enseñanza-aprendizaje para todo el año escolar. Por grado y asignatura, se dosifican y ordenan secuencialmente los contenidos y competencias del programa de estudio nacional, del programa de p'urhepecha (L1) y del programa de español (L2). Las categorías que contiene son: 1. Aprendizajes esperados; 2. Contenidos Interculturales (contenidos programáticos de las asignaturas); 3. Contenidos Intraculturales (Unidades Temáticas P'urhepecha relacionadas con los contenidos de asignatura y otros contenidos que se enseñan desde la cultura propia,); Conceptos y vocabulario p'urhepecha; 4. Aspectos y lenguaje: gramática y vocabulario de español L2.

\section{Planes semanales $y$ diarios $\Rightarrow$ Segundo nivel}

Los planes semanales tienen como función articular las categorías de los planes bimestrales (contenidos de asignatura, Unidades Temáticas P'urhepecha, programas de lengua y aprendizajes esperados), con actividades y materiales para la aplicación en el aula. Además, se espera que cada profesor, en sus actividades, programe la secuencia didáctica que tiene una clase (introducción, desarrollo, transferencia y evaluación), para cada contenido y actividad planeada, así como de las competencias lingüísticas y comunicativas de cada lengua con base en el enfoque 
del Aprendizaje Integrado de Contenidos y Lenguas (AICL). Algunos maestros elaboran también sus planes diarios.

\section{EL CURRÍCULO EN EL AULA: CONTENIDOS INTRACULTURALES PROPIOS Y CONTENIDOS DE LENGUA L1 P'URHEPECHA}

Expondremos aquí con unos ejemplos cómo funciona el currículo, sobre todo a nivel de los Planes Bimestrales, como principales instrumentos de planificación de clases en manos de los docentes, que integran contenidos y competencias de los Planes y Programas de Estudios IB P'urhepecha (PyP, Programas L1 y L2). El ejemplo escogido corresponde a una planeación colectiva del sector de las 14 escuelas p'urhepecha de la región, cuyos profesores acordaron desarrollar un tema común por mes que integre el conjunto de asignaturas.

El tema del mes para noviembre de 2016 fue Juchari icb'eri y juchari juata (nuestro territorio y bosque), principalmente del género textual nit'amakurbikua (relato histórico) que desarrollan las nanitas y tatitas k'ériicha (abuelas y abuelos). La planeación integra un conjunto de habilidades del p'urhepecha que provienen del Programa L1. La estructura discursiva del relato histórico activa categorías del lenguaje y visibiliza elementos de una pedagogía indígena basada en las funciones comunicativas que cumple la lengua p'urhepecha en la comunidad y en las familias. Desde temprana edad los niños están expuestos a escuchar diversas formas del discurso p'urhepecha y se espera que a lo largo de su proceso formativo aprendan a actuar en relación a su entorno, de acuerdo a lo esperado por los adultos, principalmente por parte de las nanitas y tatitas k'ériicha.

En su planeación para el $5^{\circ}$ grado los docentes de las escuelas participantes establecieron el tema general del mes y cuatro subtemas para cada semana:

Tema del mes: Juchari ireta ka juchari ich'eri (nuestra comunidad y su territorio) Organización semanal de subtemas y contenidos:

$1^{\text {a }}$ semana: Juchari ich'eri marhoataku (diferentes usos del territorio comunal) $2^{\text {a }}$ semana: juchari ich'eri atsikurhikua (los límites territoriales de la comunidad) $3^{\text {a }}$ semana: juchari ich'eri koakurhakua (extensión territorial de la comunidad) $4^{\mathrm{a}}$ semana: juchari ich'eri kankurhikua (las diferentes formas de posicionamiento territorial al interior de la comunidad)

Para el día martes de la segunda semana, el plan del maestro de $5^{\circ}$ grado en Uringuitiro es el siguiente: 
Cuadro 3: Planeación del día

QUINTO GRADO

\begin{tabular}{|c|c|c|}
\hline \multicolumn{3}{|c|}{ TEMA DEL MES: Nuestra comunidad y su territorio ( Juchari ireta ka juchari ich'eri ) } \\
\hline \multicolumn{3}{|c|}{$\begin{array}{l}\text { PROPOSITO: Potencializar la vida comunal y el cuidado integral del territorio de la comunidad } \\
\text { local. }\end{array}$} \\
\hline TEMA SEMANAL & $\begin{array}{l}\text { SUGERENCIA DE } \\
\text { ACTIVIDADES }\end{array}$ & $\begin{array}{l}\text { MATERIALES DE } \\
\text { APOYO }\end{array}$ \\
\hline $\begin{array}{l}\text { Los límites territo- } \\
\text { riales de la comu- } \\
\text { nidad }\end{array}$ & $\begin{array}{ll}\checkmark & \text { Mitini nani jameriski juchari ich'eri } \\
\checkmark & \text { Na xaniski juchari ich'eri } \\
\checkmark & \text { Namuni iretiicha jarhaski juchari } \\
& \text { ich'erirhu } \\
\checkmark & \text { Mitiani jamekuuchani } \\
\checkmark & \text { Uerani xanharani ka mitiani ja- } \\
& \text { mekuuchani enka no xani iauani } \\
& \text { jaka. }\end{array}$ & $\begin{array}{l}\text { Los planos técnicos de la } \\
\text { comunidad de Pamatácuaro } \\
\text { El titulo virreinal }\end{array}$ \\
\hline $\begin{array}{l}\text { Asignaturas involu- } \\
\text { cradas }\end{array}$ & $\begin{array}{l}\text { Lengua Indígena - Relatos históricos } \\
\text { (Nit'amakurhikuecha) } \\
\text { Matemáticas - Las fracciones y sus operaciones } \\
\text { Historia - Los cambios en la división política de } \\
\text { México } \\
\text { Geografía - Llanuras y montañas de México } \\
\text { Ciencias Naturales - Los ecosistemas }\end{array}$ & $\begin{array}{l}\text { Nena arhukakata jarhaski } \\
\text { juchari iche'ri } \\
\text { Ne arhukusïni icheri jucha- } \\
\text { ri parhakpinirhu } \\
\text { Na jandiski juchari icheri- } \\
\text { rhu (juatiicha, kuperiicha) } \\
\text { Nena jokurhiski mama- } \\
\text { ru jasï tsipiku juchari } \\
\text { ich'erirhu. }\end{array}$ \\
\hline
\end{tabular}

Después de una recapitulación de los temas tratados en los días pasados, el profesor pega un plano de la región en el pizarrón y le entrega además a cada alumno una hoja con un plano pequeño. Desarrolla los siguientes temas:

- Juch'ari ich'eriri koskakua (la extensión territorial)

- Juch'ari ich'eriri jameekua ka pijparhakua (límite y colindancias)

- Juch'ari ireteecha (nuestras comunidades)

- Pikurikuucha juchari iretechaari (colindantes vecinas a las comunidades, ubicación geográfica en el territorio de Pamatácuaro)

El profesor hace énfasis en la extensión territorial, la importancia de los límites y la conformación del territorio de Pamatácuaro, la comunidad central con sus comunidades anexas. Los alumnos reflexionan y analizan en un plano la ubicación 
geográfica de las comunidades dentro del territorio de Pamatácuaro, así como de las zonas (otros territorios), como refiere el profesor los grandes límites territoriales. En la clase se hace un repaso histórico del proceso en que se fueron conformando las comunidades y su origen como resguardos y defensa del territorio común. la clase ${ }^{5}$.

Veamos cómo se desarrolla la interacción entre el maestro y los alumnos en

\begin{tabular}{|c|c|c|c|c|}
\hline Turno & $\mathrm{P}$ & Línea & Texto & Observaciones \\
\hline 28 & M & 56 & $\begin{array}{l}\text { Najtsïni arieni i } \uparrow \text { cambeski i? Je? } \\
\text { ¿Qué nos dice esto? ¿qué es esto? ¿qué? }\end{array}$ & $\begin{array}{l}\text { Apertura } \\
\text { muestra la hoja impresa } \\
\text { del plano del territorio } \\
\text { de Pamatácuaro. }\end{array}$ \\
\hline 29 & As & 57 & Te. territorio $\uparrow$ & \\
\hline 30 & M & 58 & $\begin{array}{c}\text { Territorio } \downarrow \text { peru p'orhe jimbo nena arhisïni cha. } \\
\text { cambeski i? } \\
\text { pero en purhepecha, como le dicen uds ćqué } \\
\text { es esto? }\end{array}$ & \\
\hline 31 & As & 59 & $\begin{array}{l}\text { Kuirhutsikiti } \\
\text { Un mapa }\end{array}$ & Kuirhutsikiti \\
\hline 32 & M & 60 & $\begin{array}{ll}\text { Kuirhutsikata maesti. } & \text { ćperu amberi? } \\
\text { Es un mapa } & \text { cpero de qué? }\end{array}$ & Kuirhutsikata maesti \\
\hline 33 & As & 61 & $\begin{array}{l}\text { Ich'eriri } \\
\text { De la tierra }\end{array}$ & Ich'eriri \\
\hline 34 & $\mathrm{M}$ & 62 & $\begin{array}{l}\text { ¿nani anapu ich'eriri? } \\
\text { ¿de dónde es la tierra? }\end{array}$ & \\
\hline 35 & As & 63 & $\begin{array}{l}\text { Pamatacuaro } \uparrow \\
\text { Pamatácuaro }\end{array}$ & Pamatacuaro \\
\hline \multirow[t]{3}{*}{36} & \multirow[t]{3}{*}{ M } & 64 & $\begin{array}{l}\text { Ah! Majni. jiminksï jucha arhijkia eska inde arhisïni ireta } \\
\text { ma jimbo } \\
\text { Entonces ahí es donde nosotros decimos cuando de- } \\
\text { cimos que un }\end{array}$ & \multirow[t]{3}{*}{$\begin{array}{l}\text { ich'eri jatsikurhita ire- } \\
\text { teeri ma } \\
\text { ich'eri jatsikurhita ire- } \\
\text { teeri }\end{array}$} \\
\hline & & 65 & $\begin{array}{l}\text { anapu cambe? } \uparrow \text { ich'eri jatsikurhita ireteeri ma.. ich'eri } \\
\text { jatsikurhita } \\
\text { pueblo ćqué? la propiedad de tierra de una comunidad. la } \\
\text { pertenencia de tierra de una }\end{array}$ & \\
\hline & & 66 & $\begin{array}{l}\text { ireteeri... indenksïsi anchikurhini jaka jucha. ckurha- } \\
\text { xakijtsï } \uparrow \\
\text { comunidad eso es lo que estamos trabajando cestán } \\
\text { escuchando? }\end{array}$ & \\
\hline
\end{tabular}

5. Escogemos unos pocos fragmentos y dejamos de lado el análisis técnico formal de la interacción verbal. 


\begin{tabular}{|c|c|c|c|c|}
\hline 37 & As & 67 & $\begin{array}{l}\text { Jo } \\
\text { Si }\end{array}$ & \\
\hline \multirow[t]{3}{*}{38} & $\mathrm{M}$ & 68 & $\begin{array}{l}\text { Buenu ćne miantasïni? i juchari ich'eriru } \\
\text { anhaskata jarhaspti } \\
\text { Bueno ćquién se acuerda? Esto represen- } \\
\text { ta a nuestra tierra }\end{array}$ & $\begin{array}{l}\text { i juchari ich'eriru } \\
\text { anhaskata jarhaspti }\end{array}$ \\
\hline & & 69 & $\begin{array}{l}\text { para uenani jamani.. ini. ćambe ua jucha? } \\
\text { para empezar con esto ćqué necesitamos } \\
\text { hacer? }\end{array}$ & \\
\hline & & 70 & & \\
\hline 39 & $\mathrm{~A} 1$ & 71 & $\begin{array}{l}\text { Pats'ani } \\
\text { Guardar }\end{array}$ & $\begin{array}{l}\text { Pats'ani } \\
\text { Guardar } \quad((\text { resguardar, } \\
\text { cuidar }))\end{array}$ \\
\hline \multirow[t]{2}{*}{40} & \multirow[t]{2}{*}{$\mathrm{M}$} & 72 & $\begin{array}{l}\text { Pats'ani } \downarrow \text { enjkaksï jucha karanharikuaka } \\
\text { k'umandani, ci ich'eri } \\
\text { Guardar cuando nosotros escribamos en el } \\
\text { área sombreada cesta tierra }\end{array}$ & \\
\hline & & 73 & $\begin{array}{l}\text { amberiski? ¿nena arhikurisïni? } \\
\text { de qué es? ¿cómo se llama? }\end{array}$ & \\
\hline
\end{tabular}

\begin{tabular}{|c|c|c|c|c|}
\hline 41 & As & 74 & Comunidad... comunal & \\
\hline 42 & M & 75 & $\begin{array}{l}\text { ¿nenaa?:: comunidad } \downarrow \text { no comunal } \\
\text { ¿cómo? comunidad no comunal }\end{array}$ & \\
\hline 43 & As & 76 & Comunidad & \\
\hline \multirow[t]{4}{*}{44} & \multirow[t]{4}{*}{ M } & 77 & $\begin{array}{l}\text { A ver... ¿ ¿Marisela, comunal ambe arhikueksï- } \\
\text { ni? ceskichkiksï ambe } \\
\text { ¿Marisela, comunal que significa? } \\
\text { ¿qué es lo que se debe }\end{array}$ & \multirow{4}{*}{$\begin{array}{l}\text { Pregunta directament } \\
\text { a Mr } \\
\text { ¿Marisela, comunal } \\
\text { ambe arhikueksini? } \\
\text { ceskichkiksï ambe ua? }\end{array}$} \\
\hline & & 78 & $\begin{array}{l}\text { ua? Karantaspkaksï imania. ¿ne } \\
\text { miantaxaki? = caberi miakuarhintsï } \\
\text { hacer? Ya habíamos escrito cquién recuer- } \\
\text { da? ca ver, recuerden }\end{array}$ & \\
\hline & & 79 & $\begin{array}{l}\text { je }=\text { aberi ne miantaxaki? }\{\operatorname{com}\} \downarrow \text { cambe } \\
\text { arhikueksinni? = cambe arhisïni } \\
\text { a ver, cquién se acuerda? } \\
\text { decir? ¿qué quiere } \\
\text { ¿quiere }\end{array}$ & \\
\hline & & 80 & $\begin{array}{l}\text { enjka komunalika? = ¿ne miantaxaki? } \\
\text { decir cuando es comunal? ¿quién se acuerda? }\end{array}$ & \\
\hline 45 & $\mathrm{Mr}$ & 81 & $\begin{array}{l}\text { Ich'eri jatsikurhini } \\
\text { Nuestra tierra ((que tenemos tierra)) }\end{array}$ & Ich'eri jatsikurhini \\
\hline
\end{tabular}




\begin{tabular}{|c|c|c|c|c|}
\hline 46 & M & 82 & $\begin{array}{l}\text { Jo, ich'eri jatsikurhini. ċjo? } \uparrow \text { cmaterhu } \\
\text { ambe? } \\
\text { Sí, nuestra tierra ((la tierra que nos perte- } \\
\text { nece)) }\end{array}$ & \\
\hline 47 & A2 & 83 & $\begin{array}{l}\text { Pats'ani } \\
\text { Guardar }\end{array}$ & $\begin{array}{l}\text { Pats'ani } \\
\text { Cuidar, proteger }\end{array}$ \\
\hline 48 & M & 84 & $\begin{array}{l}\text { Pats’ani } \downarrow \text { ¿materhu ambe? } \uparrow \\
\text { Guaradar cqué más? }\end{array}$ & \\
\hline 49 & $\mathrm{~A} 3$ & 85 & $\begin{array}{l}\text { Juaterhu marhoaskaku } \\
\text { Los beneficios que nos brinda el cerro }\end{array}$ & Juaterhu marhoaskaku \\
\hline \multirow[t]{2}{*}{50} & M & 86 & $\begin{array}{l}\text { Ah, mentku iaminduucha marhoatani, inde } \\
\text { isï arhinksindi, kurhaaje } \uparrow \\
\text { Ah, para el beneficio de todos, } \\
\text { así se llama, escuchen }\end{array}$ & \\
\hline & & 87 & $\begin{array}{l}\text { Aberi Adolfo, parachí mentku iaminducha } \\
\text { marhoatani jucha } \rightarrow \text { anoo } \downarrow \\
\begin{array}{l}\text { A ver Adolfo, para que todos nos benefi- } \\
\text { ciemos } \quad \text { verdad }\end{array}\end{array}$ & \\
\hline
\end{tabular}

\begin{tabular}{|c|c|c|c|c|}
\hline 61 & Es & 110 & $\begin{array}{l}\text { Mentku marhoatani } \\
\text { Los aprovechamos ((diversos usos }))\end{array}$ & marhoatani \\
\hline 62 & M & 111 & $\begin{array}{l}\text { Marhoatani ¿ne? } \\
\text { Aprovecharlo cquién? }\end{array}$ & \\
\hline 63 & As & 112 & $\begin{array}{r}\text { Mentku iaminduucha } \\
\text { Completamente todos }\end{array}$ & \\
\hline \multirow[t]{3}{*}{64} & \multirow[t]{3}{*}{ M } & 113 & de una vez & \multirow{3}{*}{$\begin{array}{l}\text { As silencio prolongado, } \\
\text { no saben la respuesta }\end{array}$} \\
\hline & & 114 & $\begin{array}{l}\text { iaminduucha ka mentku indeni kutao } \\
\text { pats'axaka cambechi uo? } \\
\text { todos y estamos guardando esa casa } \\
\text { ¿qué vamos a hacer? }\end{array}$ & \\
\hline & & 115 & 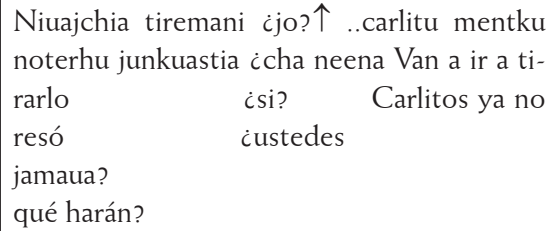 & \\
\hline
\end{tabular}




\begin{tabular}{|c|c|c|c|c|}
\hline 65 & Es & 116 & $\begin{array}{l}\text { Materhu nemani inchaatani } \downarrow \\
\text { Meterlos a otros ((gentes de la co- } \\
\text { munidad)) }\end{array}$ & \\
\hline \multirow[t]{6}{*}{66} & \multirow[t]{6}{*}{$M$} & 117 & $\begin{array}{r}\text { Ah! materhu } \uparrow \text { nemani inchaatatani } \\
\mathrm{Ah} \text { meter a otra gente }\end{array}$ & \\
\hline & & 118 & $\begin{array}{l}\text { ooti neentisiki. Adolfuniksï inchatani ooti } \\
\text { inde anoo ichaakuni irekurhini } \\
\text { podrían meter a Adolfo } \\
\text { él verdad entrar a vivir ahí }\end{array}$ & \\
\hline & & 119 & $\begin{array}{l}\text { majni indejti komunalini, eska nonema } \\
\text { jatsïska=nonema jatsïsti para } \\
\text { entonces es comunal, } \\
\text { nadie puede para }\end{array}$ & \multirow[t]{4}{*}{$\begin{array}{l}\text { M explica el signifi- } \\
\text { cado del concepto } \\
\text { komunali } \\
\text { Comunal }\end{array}$} \\
\hline & & 120 & $\begin{array}{l}\text { arini jucheusti inde. eskichinha jucha uaka } \\
\text { inchakuni naniuejkini } \\
\text { decir esto es mío que nosotros podamos } \\
\text { entrar en donde sea }\end{array}$ & \\
\hline & & 121 & $\begin{array}{l}\text { uakanha jucha inchakuni } \downarrow_{\text {oakaksï- }} \\
\text { nha jucha inchakuni chukari ambe } \\
\text { que podamos nosotros entrar podamos } \\
\text { nosotros entrar por a cortar }\end{array}$ & \\
\hline & & 122 & $\begin{array}{l}\text { pikuni. mamambe. peru nombe para uni } \\
\text { ¿nena arhisïani? } \uparrow \\
\text { leña muchas cosas pero para no hacerlas } \\
\text { ¿cómo se llama? }\end{array}$ & \\
\hline 67 & $\mathrm{Mr}$ & 123 & $\begin{array}{l}\text { Para kutao uaani } \\
\text { Para hacer casas }\end{array}$ & \\
\hline
\end{tabular}




\begin{tabular}{|c|c|c|c|c|}
\hline 68 & M & 124 & $\begin{array}{l}\text { Para kutao urhani anoo, iperu pedru } \\
\text { intsauajtsïni? } \uparrow \\
\text { Para construir casas, verdad ipero pedro } \\
\text { nos dará? }\end{array}$ & Confuso \\
\hline 69 & As & 125 & $\begin{array}{l}\text { Nombe } \\
\text { No }\end{array}$ & \\
\hline \multirow[t]{5}{*}{70} & \multirow[t]{5}{*}{ M } & 126 & $\begin{array}{l}\text { ¿Nombe anoo? Jimani inde jindeesti juchari } \\
\text { ich'eri anchintasïnka } \\
\text { ¿No verdad? Entonces eso es nuestro } \\
\text { territorio trabajamos nuestra }\end{array}$ & \multirow{5}{*}{$\begin{array}{l}\text { presenta mapa plano } \\
\text { impreso en la hoja de } \\
\text { papel } \\
\text { muestra mapa } \\
\text { papá k'eri (se utiliza } \\
\text { para abuelo que signifi- } \\
\text { ca papá grande) } \\
\text { M en la línea } 127 \text { in- } \\
\text { siste en el llamado de } \\
\text { atención al articular la } \\
\text { siguiente frase "aberi } \\
\text { xeje iasï" }\end{array}$} \\
\hline & & 127 & $\begin{array}{l}\text { komunali, eska mentku iaminduchee- } \\
\text { riska.. ah! aberi xeje iasi } \uparrow \\
\text { tierra comunal } \\
\text { ah a ver miren ahora }\end{array}$ & \\
\hline & & 128 & $\begin{array}{l}\text { Estrellitani kuramarhiaka ji. ćcheri papá k'éri } \\
\text { ambe utspinini jamaxaki } \\
\text { Le voy a preguntar a Estrellita ctu abuelo } \\
\text { que actividad anda }\end{array}$ & \\
\hline & & 129 & $\begin{array}{l}\text { jiminisï, ambe uski ima? } \uparrow \text { cnemitiski? } \uparrow \text { Mi- } \\
\text { guelitu mititi, cneeski } \\
\text { apoyando, que ha hecho él? ¿quién sabe? } \\
\text { Miguelito debe saber cquién }\end{array}$ & \\
\hline & & 130 & $\begin{array}{l}\text { materhu xu? Mmm. Sanderu sani Miguelitu. } \\
\text { cambeksï uspki } \\
\text { más aquí? Más cercano Miguelito } \\
\text { ¿qué es lo que hicieron } \\
\text { jiniani? } \uparrow \\
\text { allá? }\end{array}$ & \\
\hline
\end{tabular}

Inicia el tema de territorio. El maestro (M) distribuye copias del plano del territorio de Pamatácuaro, la comunidad p'urhepecha central de la que dependen las 14 comunidades menores. El $\mathrm{M}$ formula una pregunta muy general que permite varias respuestas. Los alumnos contestan en español "territorio" (turno 29). El M no acepta la respuesta en español e insiste en una respuesta en p'urhepecha. Los alumnos, otra vez en forma colectiva, ensayan otra respuesta, esta vez en p'urhepecha, y el M los conduce a la respuesta esperada (31-36). Con el "ah" $M$ cierra la secuencia con una evaluación positiva. Sigue con una primera formulación y reformulación del concepto central icb'eri jatsikurbita ma, icb'eri jatsikurbita ireteeri (la propiedad de tierra de una comunidad, la pertenencia de y a tierra de una comunidad).

El M realiza una nueva apertura y continúa con el recordatorio del tema. Reformula la pregunta con el concepto central ii juchari ich'erirhu anhaskata 
jarhasti? (cesto representa a nuestra tierra?) (38). Dicha pregunta es una aproximación cercana a la conceptualización de juchari ich'eri (nuestro territorio). El M amplía el interrogatorio consultando las acciones que requiere el territorio. Los alumnos responden pats'ani (guardar) que en este contexto significa al acto de cuidar, proteger, resguardar (39). Sin embargo, el $M$ no se da por satisfecho con la respuesta e insiste ¿nena arhikurisïni? (¿cómo se llama?). Los alumnos responden en español "comunidad - comunal" (41). La insistencia del M y su reformulación del término (42) indican que espero otra respuesta que finalmente la da Marisela (45); sigue una confirmación del M (46) y se reabre la ampliación temática. A2 responde pats'ani (guardar, resguardar, proteger) (47); esta noción simboliza el núcleo de la conceptualización del territorio. Es un marcador histórico de defensa al territorio y remite a la fundación de las catorce comunidades, entre ellas la comunidad de San Isidro, en los linderos del territorio de Pamatácuaro para la defensa del centro contra invasiones desde afuera por otras comunidades p'urhepechas. Juaterbu marboaskaku (los beneficios que nos brinda el cerro) aparece como cómo eje articulador de los beneficios que otorga el territorio, específicamente el cerro como territorio.

Un poco más tarde se desarrolla una interacción rápida de cascada entre un alumno (Es, 61), el My el refuerzo en coro de los conceptos que simbolizan los beneficios de pertenecer a un territorio marboatani (los usos, beneficios); este concepto es el principal para la relación que existe entre la comunidad y el territorio (la tierra, los cerros) (61-64). A continuación, el M explica el significado de komunali, un préstamo del español, que expresa el sentido de propiedad comunitaria a partir del respeto a los espacios territoriales. Nadie puede entrar donde quiera y decir esto es mío, o puede entrar a cortar leña. El M explica por qué en la actualidad los p'urhepecha viven en comunidad y en relación con la tierra. Señala a los alumnos el concepto de comunidad y comunal a partir del ejemplo de un señor que entra a un espacio que no le pertenece y debate qué se puede hacer en los terrenos propios. Se nota que el maestro tiene dificultades para que los alumnos relacionen el concepto de comunidad con los derechos y obligaciones en ese espacio.

En otro momento de la clase el $\mathrm{M}$ tematiza el concepto de linderos entre propiedades y los conflictos que surgen cuando entre vecinos no se respetan las demarcaciones de territorio. Los conceptos que trabaja son:

- Pikurhikia - lindero (concepto central y eje rector en el desarrollo de la clase).

- No sesi arhijperhakua - decir de mala manera (decir cosas feas)

- Arhinchperani-criticarse

- P'akani- empujar, recorrer el lindero

- Jamekua - límites de propiedad 


\begin{tabular}{|c|c|c|c|c|}
\hline 27 & $\mathrm{M}$ & 42 & $\begin{array}{l}\text { Ahhh, ¿ne euantaski ima? } \\
\text { ca quién se los quitó? }\end{array}$ & \\
\hline 28 & A5 & 43 & $\begin{array}{r}\text { Imani } \\
\text { A ellos }\end{array}$ & \\
\hline \multirow[t]{3}{*}{29} & \multirow[t]{3}{*}{$M$} & 44 & $\begin{array}{l}\text { Juanita ćch'a ia? } \\
\text { Juanita cy ustedes? }\end{array}$ & \multirow{3}{*}{$\begin{array}{l}\text { M en la línea } 46 \text { pre- } \\
\text { gunta, pero no se dis- } \\
\text { tingue en absoluto la } \\
\text { respuesta de A6 }\end{array}$} \\
\hline & & 45 & $\begin{array}{l}\text { ¿nojtsï ambe ma arhisperasïni jimaasï? cje? ¿ch’a } \\
\text { jo? cnee cha jinkoni } \\
\text { cno existen por ahí algunos problemas? ¿qué? } \\
\text { custedes si? ćcon quiénes }\end{array}$ & \\
\hline & & 46 & $\begin{array}{lc}\text { arhinchperasïni? } & \text { cambe uní? } \\
\text { Tienen problemas } & ((\text { se dicen cosas }))\end{array}$ & \\
\hline 30 & A6 & 47 & $\begin{array}{l}\text { Taku uajpa xuani k'uaniatasindi basura } \\
\text { El hijo de Taku avienta de este lado la basura }\end{array}$ & \\
\hline 31 & $\mathrm{M}$ & 48 & $\begin{array}{l}\text { ¿ne ia? } \\
\text { ¿quién dices? }\end{array}$ & \\
\hline 32 & A6 & 49 & $\begin{array}{l}\text { Taku uajpa } \\
\text { El hijo de Taku }\end{array}$ & \\
\hline
\end{tabular}

\begin{tabular}{|c|c|c|c|c|}
\hline \multirow[t]{3}{*}{33} & \multirow[t]{3}{*}{$\mathrm{M}$} & 50 & $\begin{array}{l}\text { iah! cima ch'eni k’uni k’uaniatasïni? Bueno... } \\
\text { iah! cél avienta en tu casa la basura? }\end{array}$ & \\
\hline & & 51 & $\begin{array}{l}\text { Mamambe jarhajti inde -ch'ajteru ćch'entu? cambe } \\
\text { jarhaski ch'entuia? } \\
\text { Se presentan varias cosas-ustedes cen tu casa? } \\
\text { ¿qué hay también en tu casa? }\end{array}$ & \\
\hline & & 52 & $\begin{array}{l}\text { ¿ambe usïni ima? } \\
\text { ¿qué hace él? }\end{array}$ & \\
\hline 34 & $\mathrm{~A} 1$ & 53 & $\begin{array}{l}\text {... imajtsïni juchantsïni ich'eri p’akachisti... } \\
\text { ellos a nosotros nos empujaron nuestra tierra } \\
\text { (significa que los vecinos fueron empujando el lí- } \\
\text { mite de la propiedad comunal, bien puede ser el } \\
\text { lindero) }\end{array}$ & $\begin{array}{l}\text { No se percibe bien la } \\
\text { que dice A1 } \\
\text { Introduce concepto } \\
\text { clave ich'eri paka- } \\
\text { chisti (significa que } \\
\text { los vecinos se fueron } \\
\text { adueñando del limite } \\
\text { de la propiedad fami- } \\
\text { liar) }\end{array}$ \\
\hline 35 & $\mathrm{M}$ & 54 & $\begin{array}{l}\text { iah ima ich'eri p’akasti, exe! } \\
\text { iah! él se adueñó de una parte de la tierra, imira! }\end{array}$ & As ríen \\
\hline
\end{tabular}


El $\mathrm{M}$ inquiere a sus alumnos sobre conflictos que ellos mismos han vivido con sus familias y con vecinos por problemas de terrenos y linderos (27-33). Un alumno (A1) responde utilizando el término importante de ich'eri p'akachisti, empujaron nuestra tierra (34), y el maestro extiende el concepto como un término ich'eri p'akasti de invasión o apropiación de determinada propiedad familiar (35). Luego expande el tema con el relato de la experiencia histórica que han tenido las comunidades pertenecientes al territorio de Pamatácuaro con Patamban, otra comunidad grande y poderosa, con la cual existe un conflicto histórico. Resalta los problemas que siempre tuvieron los pats'ariicha, los que cuidan, principalmente los antepasados, en la protección del territorio.

En síntesis, constatamos que los docentes preparan unidades temáticas en que desarrollan conceptos centrales de la identidad p'urhepecha a nivel local y regional. En el caso analizado, nos percatamos de las dificultades que tiene el maestro, sobre todo al inicio, cuando quiere desarrollar una conceptualización de un campo semántico y conceptual desde la cosmovisión p'urhepecha, sin pasar por las categorías en español que representan las conceptualizaciones de la sociedad nacional. Se produce una intensa negociación en la interacción, ya que los alumnos recurren a conceptos del español como territorio y comunidad. Esta reacción espontánea de los alumnos de $5^{\circ}$ grado nos da un indicio hasta qué punto estos jóvenes preadolescentes de 11 años ya muestran la presencia de valores, conceptualizaciones, taxonomías y términos de la sociedad mexicana general, a pesar de que en su mayoría tienen un conocimiento muy limitado de la sociedad nacional, casi no han salido de la región inmediata y cuyo dominio del español es precario. Estos episodios en clase confirman, por un lado, la preocupación de muchos maestros que determinadas actividades, rituales y conceptualizaciones del pueblo p'urhepecha ya no se transmitan plenamente a las nuevas generaciones; muestran, por otro lado, los amplios espacios y la receptividad entre los jóvenes que tiene una política consecuente de fortalecer y revitalizar una identidad étnica a partir de las taxonomías y cosmovisiones indígenas y el sistemático uso del p’urhepecha como vigoroso valor nuclear de la identidad y a la vez vehículo eficiente para su reforzamiento.

Podemos representar el proceso de planeación-implementación descrito con el siguiente esquema: 


\section{Cuadro 4: Planificación de las unidades sobre juchari ich'eri (territorio).}

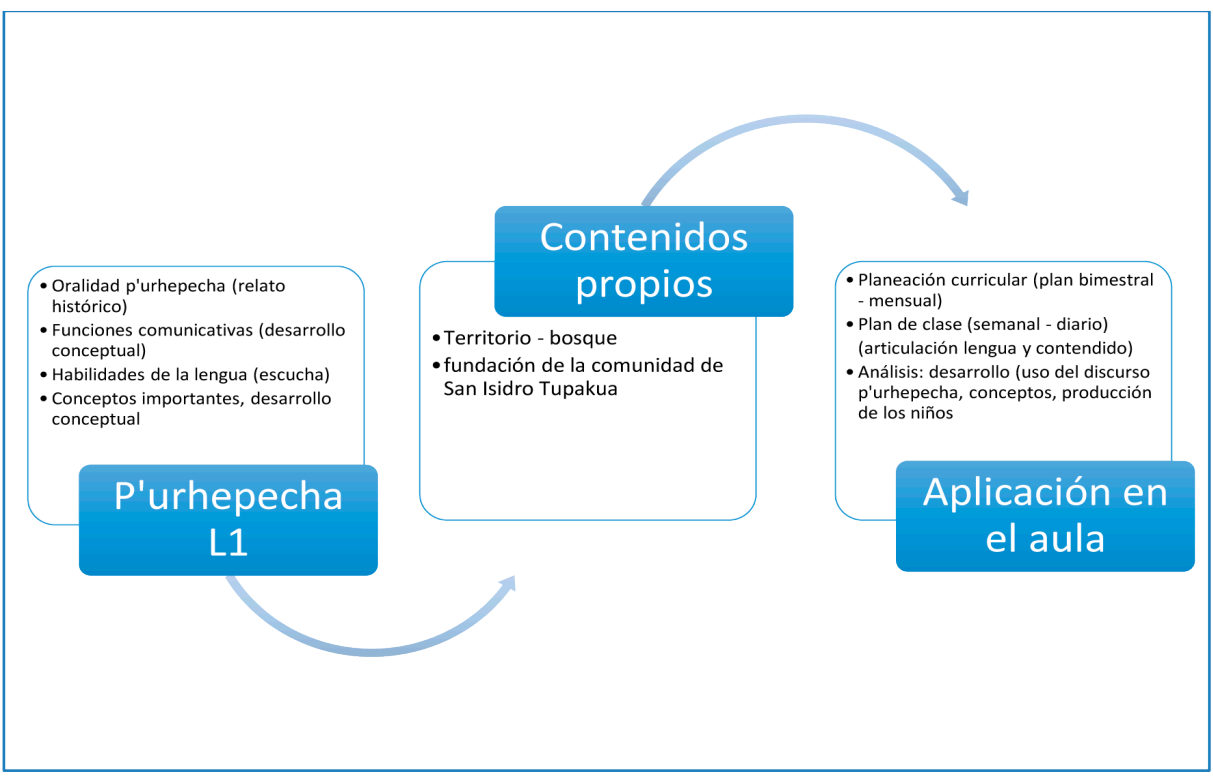

\section{LA RIQUEZA MORFOLÓGICA DEL P'URHEPECHA COMO FUENTE DE ENRIQUECIMIENTO DIDÁCTICO EN LA ENSEÑANZA DE LAS MATEMÁTICAS}

Veamos otro caso muy sugerente que demuestra la validez de una construcción sofisticada, enriquecedora e integrada de currículo, enseñanza, lengua e identidad étnica en el micro-nivel de la planeación y puesta en práctica en el salón de clase.

A partir de las investigaciones sobre cómo funcionan los instrumentos curriculares del proyecto en los salones de clases, ubicamos algunos casos representativos de la relación entre contenidos de matemáticas y la lengua p'urhepecha. Como ya vimos, el diseño de los Programas construye una articulación transversal de lenguas y asignaturas a través del enfoque del Aprendizaje Integrado de Contenidos y Lenguas (AICL). Esta orientación nos llevó a preguntarnos de qué manera se relaciona el p’urhepecha con la enseñanza y el aprendizaje de fracciones matemáticas en el aula.

\subsection{Planeación de clase: matemáticas occidentales en p'urhepecha}

Para responder a esta pregunta proponemos hacer un análisis en tres niveles: el del currículo, que identifica los contenidos y competencias de la asignatura y del 
p'urhepecha (L1) para tercer grado; el de la planeación, que incluye una lista de actividades así como conceptos, vocabulario y aspectos del lenguaje que apoyan la enseñanza; y el del salón de clases, en donde todo los ingredientes anteriores se ponen a trabajar en la construcción interactiva de eventos y sentidos escolares.

\section{Primer nivel: contenidos y competencias de las matemáticas y la L1}

En este nivel distinguimos el contenido de la asignatura de matemáticas y el contenido de lengua (L1) para ver cómo estos componentes están diseñados y cuáles son sus implicaciones en el proceso de enseñanza y aprendizaje. En el caso que presentamos como ejemplo, la estructura es la del Plan de Estudios ${ }^{6}$ que organiza la asignatura en ejes, temas y contenidos a lo largo de toda la educación básica. Para las matemáticas encontramos el eje: sentido numérico y pensamiento algebraico; el tema: números y sistemas de numeración, con el contenido: identificación de escrituras equivalentes (aditivas, mixtas) con fracciones. El contenido de lengua L1 contiene los clasificadores de forma ich'akua (largo), ich'ukua (plano), irbakua (redondo) y formas de dividir objetos kuarbatiicha(ni) (para objetos largos), karokatiicha(ni)/ kacb'ukuni (para objetos planos) y kapekatiicha (para objetos redondos).

Para la enseñanza y el aprendizaje de números fraccionarios se requiere del manejo y la comprensión de una multiplicidad de nociones abstractas para representar la división, reparto y asociación de las partes de un todo, que tiene además escrituras equivalentes según la situación o el problema. Lo anterior supone un reto para maestros y alumnos, pues según la Guía para el maestro de los Programas de Estudio (2011) el aprendizaje de las fracciones constituye "una de las áreas de mayor falla en las escuelas a nivel mundial, junto con los números decimales" (p 334); por esta razón, recomiendan a los profesores tomar en cuenta que "es importante que los alumnos 'descubran' y comprendan que, dependiendo de la situación, las fracciones adquieren distintos significados y que éstas, pueden ser representadas de diversas formas" (p. 334 cursivas nuestras).

Observamos entonces la importancia de la conceptualización en la comprensión de los números fraccionarios, particularmente cómo la representación dota de sentido a esta noción. Es justo en esta parte donde articulamos las formas del p'urhepecha que apoyan este proceso pues, como vimos más arriba, esta lengua cuenta con morfemas que asignan una característica física/espacial a los objetos:

6. Nos referimos aquí a los materiales de la Reforma Integral de Educación Básica (RIEB) que la Secretaría de Educación Pública implementó desde el año 2011 y hasta este pasado ciclo escolar 2017-2018. 
largo, plano y redondo, y que, dependiendo de dicha propiedad, también se le asignará un verbo para denominar las diferentes formas de descomponer un objeto entero.

Hay cinco verbos que entran en juego: kapekuni es la acción de quebrar objetos planos como vidrios, barros, tablas, o también algo esférico o redondo como una naranja o una manzana; karokuni designa la acción de cortar y se puede aplicar a las formas anteriores, pero mejor a materiales como papel y telas; uarbokuni también refiere a la acción de cortar, pero se aplica en objetos alargados y gruesos (como madera en rollo y varas gruesas), también se usa para objetos semi-redondos de tamaño grande como una sandía o un melón; kuarbakuni es la acción de quebrar objetos alargados (varitas, un lápiz, una caña); kach'ukuni se usa para cortar objetos alargados o planos, pero delgados. Los profesores nos comentaron que estas acciones también pueden depender de qué herramienta o cuanta fuerza se necesita para llevar a cabo la tarea de partir, cortar o quebrar.

\section{Segundo nivel: planeación}

Este nivel es muy importante para vincular el currículo IB del proyecto con lo que sucede en las aulas, pues los profesores seleccionan de los Planes Bimestrales (PB) los contenidos y competencias por asignatura, así como los componentes de la lengua que les pueden servir a la hora de planear sus clases y aplicarlos en los salones de clases. Recordemos que el maestro toma formas del p'urhepecha para enseñar contenidos de matemáticas ${ }^{7}$. En este caso recapitula en un inicio las maneras de dividir objetos para aplicarlo después a la fracción de números. Vemos aquí cómo

7. Obviamente, no estamos hablando de la enseñanza de matemáticas indígenas, o de las formas culturalmente diferenciadas en que distintos pueblos pueden formular y organizar las leyes generales de las matemáticas. Recordemos que la lengua p’urhepecha tiene la función importante de vehicular el conjunto de contenidos curriculares, para lo cual se llevó a cabo un extenso proceso de Sprachausbau (elaboración de la lengua, KLOSS, 1978). Este proceso no sólo incluye la creación de vocabulario con un propósito didáctico, sino también la activación de estructuras semántico-conceptuales gramaticalizadas en la morfología del p'urhepecha que pueden constituir herramientas didácticas valiosas para la enseñanza de conceptualizaciones matemáticas abstractas como las fracciones o el cuadro cartesiano que no forman parte de la cosmovisión infantil de ninguna cultura, ni siquiera de los niños en la Francia de Descartes. Véase una crítica interesante a nuestro trabajo de Alicia Ávila (2018) que, sin embargo, yerra su blanco porque no distingue entre el trabajo con conceptualizaciones espacio-temporal indígenas que contienen componentes matemáticos, lo que realiza ella en su investigación, y la enseñanza de las matemáticas occidentales en lengua indígena. En este último caso, los neologismos didácticos en p'urhepecha resultaron ser de un gran valor pedagógico, como lo demuestra nuestro trabajo conjunto de muchos años en las escuelas indígenas. 
opera la función o uso de la lengua en la representación de las nociones de unidad y fracción.

La planeación del maestro define en la columna "iqué voy a enseñar?" las competencias y contenidos de la asignatura de matemáticas, mientras que en la columna "ccómo lo van a aprender?" detalla las actividades y la propuesta de vocabulario.

Cuadro 4: Plan de clase de matemáticas

\begin{tabular}{|c|c|c|c|c|c|}
\hline \multicolumn{2}{|c|}{ ¿QUÉ VOY A ENSEÑAR? } & $\mathrm{L}$ & \multicolumn{3}{|c|}{ ¿CÓMO LO VAN A APRENDER? } \\
\hline Competencias & Contenidos & & Actividades & $\mathrm{T}$ & Vocabulario \\
\hline $\begin{array}{l}\text { Identificar } \\
\text { escrituras } \\
\text { equivalentes } \\
\text { con } \\
\text { fracciones. } \\
\text { Comparar } \\
\text { fracciones en } \\
\text { casos } \\
\text { sencillos }\end{array}$ & $\begin{array}{l}\text { Identifica } \\
\text { escrituras } \\
\text { equivalentes } \\
\text { (aditivas, } \\
\text { mixtas) con } \\
\text { fracciones }\end{array}$ & L1 & $\begin{array}{l}\text { Irakontani kapekata, karokata, kuarhakata ka } \\
\text { tirokutantani majku kanhaniichani. } \\
\text { Escoger los que están recortados, partidos y divididos } \\
\text { y juntar los que están iguales. } \\
\text { Manharhitakoni t'amu ichuku sïrantiichani, } \\
\text { unharhikakata ma jinkuni enkaklsï tachani kanhani } \\
\text { arhukatiicha jukanharhini. } \\
\text { Pegar en cuatro hojas en donde se contengan } \\
\text { diferentes cantidades. } \\
\text { Tirojani, t'apuru, tempini kuipuru, ma ik'uatsi ka } \\
\text { tempini tsimanipuru Tirokutantani ampe jimpo } \\
\text { torokurhentasini ka ampe jimpo un tirokurhentasinni. } \\
\text { Un medio, cuatro dieciseisavos y ocho treintaidosavos } \\
\text { para compararlos por qué se comparan y por qué no se } \\
\text { comparan. } \\
\text { Urharhikooto papel china jompo ka kapinharhitati } \\
\text { unharhikakaticharhu ka isï modu pit'aati iratsi ka } \\
\text { uantontskurhintsku. } \\
\text { Los escribirá y en papel china los pegará y de esta } \\
\text { manera resolverá, piensa la explicación. } \\
\text { Ka isï jamapani miteeti inteni miiuraku jimpo } \\
\text { t'antsirakuuchani } \\
1 / 2,2 / 4,4 / 16,8 / 32 \\
\text { De esta manera conocerá los números señalados } 1 / 2, \\
2 / 4,4 / 16,8 / 32 \\
\text { Ka isi mitipani unharhikuntati interi tak'ukatarhu. } \\
\text { Una vez que los identifiquen bien, los escribirá en su } \\
\text { libreta. }\end{array}$ & 1 & $\begin{array}{l}\text { Kapekata } \\
\text { Quebrados (forma de } \\
\text { dividir) } \\
\text { Karokata } \\
\text { Cortados (forma de } \\
\text { dividir) } \\
\text { kuarhakata } \\
\text { Quebrado, partido } \\
\text { arhukuni } \\
\text { fraccionar } \\
\text { tirojkani } \\
\text { mitad } \\
\text { tirojkaniri } \\
\text { mitad de la mitad }\end{array}$ \\
\hline
\end{tabular}

\section{Tercer nivel: la aplicación en el aula}

Una vez realizada la observación y el registro de la clase, procedemos a realizar el análisis de las interacciones en este espacio. El primer paso es la transcripción de todo el evento en su conjunto para elaborar una "segmentación gruesa" que nos dé cuenta de las fases o unidades de enseñanza que se trabajaron; posteriormente se seleccionan fragmentos de cada unidad para proceder con el análisis fino, turno por turno, a manera de reconstruir los sentidos que se generan a 
través de las interacciones entre maestro y alumnos en cada parte de la clase y cómo éstos apoyaron el proceso de enseñanza y aprendizaje. La clase que presentamos aquí cuenta con las tres unidades típicas de organización: introducción, desarrollo y evaluación.

\subsection{La interacción en el aula}

\section{Introducción "diferentes formas de dividir"}

En esta unidad el profesor trabaja con las diferentes formas de dividir un objeto, desde el p'urhepecha, como una forma de introducir el tema y de repasar lo que ya han visto respecto a las fracciones. Con este objetivo, pasó a algunos alumnos al frente a escribir algunas cantidades y sumas que involucran fracciones y números enteros $(1+2 / 5,3+3 / 9,5 / 3,4 / 2)$

\section{Desarrollo "en cuantas partes se va a dividir"}

Una vez que se escribieron las fracciones en el pizarrón, el maestro les pidió a los alumnos que sacaran los papelitos que usaron el día anterior y que se juntaran en los equipos que habían formado previamente para representar cada una de las fracciones escritas ${ }^{8}$. En esta parte hubo muchas interacciones entre pares y de los equipos con el profesor.

\section{Evaluación}

Cuando los equipos terminaron con la representación de fracciones, el profesor les indicó que guardaran los papelitos y que sacaran su Libro de Texto en la página 106 para resolver los problemas de manera individual. Después de unos minutos, el maestro dirigió una interacción Interrogación-Respuesta-Evaluación (IRE) en donde se resolvieron y reflexionaron los problemas colectivamente.

Enseguida presentamos algunos fragmentos representativos de cada unidad a manera de mostrar el uso de los morfemas en p'urhepecha en las interacciones de la clase de fracciones matemáticas. Como vemos, el Maestro (M) inicia con la referencia a la asignatura en la que van a trabajar y solicita a los alumnos (Aos) recordar lo que han estado trabajando e introduce el tema con la pregunta sobre si los números pueden brincar. Este input genera una serie de turnos entre $\mathrm{M}$ y

8. En el caso de los equipos que trabajaron con las ecuaciones, se trabajó primero en la resolución y después se representó el resultado de las sumas. 
Aos que van develando las categorías p’urhepechas en relación a diversos tipos de números.

\begin{tabular}{|c|c|c|}
\hline $\mathrm{L}$ & IA & $\begin{array}{c}\text { Texto } \\
\end{array}$ \\
\hline 1 & $\begin{array}{l}\mathrm{M} \\
\mathrm{tr}\end{array}$ & $\begin{array}{l}\text { a ver matematikiri numiruchirichi ambechi xespi, najarati numiruchini xespi, tsakuatesïnichi numiruchini } \\
\text { en matemáticas en los números ¿qué fue lo que vimos? ¿qué tipo de números vimos? ¿los números pueden brincar? }\end{array}$ \\
\hline 2 & $\begin{array}{l}\text { A0 } \\
\text { tr }\end{array}$ & $\begin{array}{l}\text { kach'ukatichini } \\
\text { los que se pueden dividir }\end{array}$ \\
\hline 3 & $\begin{array}{l}\mathrm{M} \\
\mathrm{tr}\end{array}$ & $\begin{array}{c}\text { jo kach'ukatichani maturu ia } \\
\text { sí los que se pueden dividir ¿cuál otro? }\end{array}$ \\
\hline 4 & $\begin{array}{l}\text { Aos } \\
\text { tr }\end{array}$ & $\begin{array}{r}\text { kuarakatichani } \\
\text { los que se pueden cortar } \\
\end{array}$ \\
\hline 5 & $\begin{array}{l}\text { M } \\
\text { tr }\end{array}$ & $\begin{array}{c}\text { kuarakatichani, maturu ia } \\
\text { los que se pueden cortar, ¿cuál otro? }\end{array}$ \\
\hline 6 & $\begin{array}{l}\text { Alg } \\
\text { tr }\end{array}$ & $\begin{array}{ll}\text { kapekatichani } & \text { IC } \\
\text { los que se pueden quebrar } & \end{array}$ \\
\hline
\end{tabular}

Nos interesa resaltar el uso de los diferentes morfemas que refieren a la acción dividir, cortar y quebrar objetos (líneas 2, 4, 6). La importancia del uso diferenciado en la clasificación p'urhepecha convierte estos elementos en metáforas pedagógicas que apoyan el proceso de enseñanza-aprendizaje, además de mostrar empíricamente la relación entre un contenido y la L1 de los alumnos. A nivel comunicativo se observa cómo comienza a construirse y negociar el sentido del evento, que en este caso corresponde a la asignatura y contenido que se va a trabajar.

Más adelante en la clase, durante el desarrollo, el My los Aos interactuaron mucho en sus equipos respecto a la solución del problema que se les pidió. Observamos que se relacionaron las representaciones en los papelitos y en su forma numérica.

\begin{tabular}{|c|c|c|}
\hline 1 & $\begin{array}{l}\text { M } \\
\operatorname{tr}\end{array}$ & $\begin{array}{l}\text { nena onteua parichi, parichi oka parika oka uentani cuenta nena arinichi (SEÑALA) ambe ontaksïni nachi } \\
\text { ¿cómo podemos contarlos para que nos salga la fracción? cuenta a este (SEÑALA) en cuánto lo vamos a convertir }\end{array}$ \\
\hline 2 & $\begin{array}{l}\mathrm{M} \\
\mathrm{tr}\end{array}$ & $\begin{array}{l}\text { xani karokundaksïni parichi menkuni jajkunduni eska ande, namupuruch'i untaksï } \\
\text { en cuántas partes la vamos a cortar para que nos salga igual que ese, en cuántas partes lo vamos a convertir }\end{array}$ \\
\hline 3 & $\begin{array}{l}\text { Aa } \\
\operatorname{tr}\end{array}$ & $\begin{array}{l}\text { cincupuru } \\
\text { en cinco partes }\end{array}$ \\
\hline 4 & $\begin{array}{l}\mathrm{M} \\
\mathrm{tr}\end{array}$ & $\begin{array}{l}\text { siete ambepini ia } \\
\text { ¿siete qué? }\end{array}$ \\
\hline 5 & Aa2 & seis, jsiete! \\
\hline
\end{tabular}

En este fragmento vimos cómo este equipo resolvió la primera ecuación (un entero más dos quintos) para poder representar el resultado en los papelitos. De 
nuevo destacamos el uso del morfema y la noción de "convertir" en partes (línea 2) que sirven de input en las preguntas del $\mathrm{M}$ y desencadenan secuencias interactivas, en este caso con dos Alumnas (Aa).

Cuando terminó este ejercicio, la unidad de evaluación se realizó con la solución de un par de problemas del libro de texto (p.106). Aquí presentamos un fragmento que refiere al inciso b del problema 2: "Un conejo, una rana y un chapulín tienen que cruzar un puente que mide 2 metros de largo. El conejo da saltos de 1/2 metro, la rana de $1 / 4 \mathrm{y}$ el chapulín de $1 / 8$. Contesten las siguientes preguntas:

a) ¿Cuál de los tres animales da saltos más largos?

b) Si el conejo da 3 saltos, la rana 6 y el chapulín 12, ¿qué distancia ha recorrido cada animal?"

\begin{tabular}{|c|c|c|}
\hline $\mathrm{L}$ & IA & Texto \\
\hline 1 & Aos & $\begin{array}{lll}\text { (ESCRIBEN) } & \text { (SE LEVANTAN) } & \text { (HABLAN) }\end{array}$ \\
\hline 2 & $\begin{array}{l}\mathrm{M} \\
\mathrm{tr}\end{array}$ & $\begin{array}{l}\text {... a ver, kurankisïje, a ver na arhisïni (SE ACERCA a Aas) } \\
\text { el libro ... a ver, comprendan ¿qué es lo que les dice el libro? }\end{array}$ \\
\hline 3 & $\mathrm{Aa}$ & (LEE LT) si el conejo da 3 saltos, la rana 6 y el \\
\hline 4 & $\mathrm{Aa}$ & chapulín 12 ¿qué distancia ha recorrido cada animal? \\
\hline 5 & $\begin{array}{l}\mathrm{M} \\
\mathrm{tr}\end{array}$ & $\begin{array}{c}\text { na axani kaniku tsankuarisïni auani } \\
\text { ¿cuánto está saltando el conejo? }\end{array}$ \\
\hline 6 & $\mathrm{Aa} 2$ & saltos \\
\hline 7 & $\begin{array}{l}\text { M } \\
\text { tr }\end{array}$ & $\begin{array}{l}\text { na xani tsankuarisïni } \\
\text { ¿cuánto saltó? }\end{array}$ \\
\hline 8 & Aal & un medio \\
\hline 9 & $\mathrm{Aa} 2$ & un medio \\
\hline 10 & $\begin{array}{l}\mathrm{M} \\
\operatorname{tr}\end{array}$ & $\begin{array}{ll}\text { enkaksï tanimu sïniaru tsakuarisïnka, na xani kaniku tsankuarisïni } & \text { ma ka medio turi jimpo nenachi arheia } \\
\text { cuando hacen tres saltos ¿en cuánto se convierte? } & \text { uno y medio ¿cómo le decimos en español? }\end{array}$ \\
\hline 11 & $\begin{array}{l}\mathrm{Aa2} \\
\mathrm{tr}\end{array}$ & $\begin{array}{l}\text { ma ka med.// } \\
\text { uno y med../ }\end{array}$ \\
\hline 12 & $\mathrm{Aa} 2$ & un entero.. \\
\hline 13 & $\mathrm{M}$ & un entero mÁs.. \\
\hline 14 & Aal & más un medio \\
\hline
\end{tabular}

Llama la atención de qué manera se va resolviendo el problema en la interacción entre $\mathrm{M}$ y Aos, En un primer momento, resaltamos la relación o equivalencia entre números enteros y fraccionarios en una situación específica; seguido a esto, está la asociación entre el "uno y medio" (líneas 8-9) que corresponde a tres saltos y la expresión "un entero más un medio" que resulta al final (líneas 12-14) como la solución correcta para el caso del conejo. La comunicación se da en p'urhe a pesar de que el material de matemáticas para la educación básica está en español. Observamos aquí una estrategia didáctica bilingüe general del proyecto escolar: a falta de libros de texto adecuados en p'urhepecha, los maestros desarrollan sus 
clases completamente en lengua indígena, incluyendo el vocabulario técnico; y usan los textos del libro en español, lo que fomenta la adquisición de la habilidad lectora del español que se adelanta al desarrollo de las demás habilidades en L2.

\subsection{Reflexiones generales}

El primer punto a destacar es la relación entre contenidos de asignatura (matemáticas) y el p'urhepecha. Resaltan dos particularidades: la primera es el input que ofrece la lengua más fuerte de los Aos para ampliar los usos de esta lengua indígena y apoyar la enseñanza de matemáticas: hay cierto equilibrio entre lengua y contenido. Para esto es importante subrayar la manera cómo se construyen las relaciones entre las formas y categorías del p'urhe y los contenidos de esta asignatura, lo que rompe con el prejuicio muy extendido de que las lenguas indígenas sólo pueden servir para ciertos contenidos de la cultura propia, pero de ninguna manera para materias tan "serias" como las matemáticas. Nos percatamos que, para referirse a un objeto se requiere de un morfema (clasificador de forma) y que para dividirlo o fraccionarlo, se cuenta con un repertorio de verbos que especifican el tamaño y la herramienta que se use para cortarlo. Al mismo tiempo, observamos cómo esta característica del p'urhepecha se aprovechó para introducir un contenido, lo que "traduce" esta forma de representación desde la lengua al trabajo con los números fraccionarios al producir otras representaciones a través de las imágenes en los papeles y en la resolución de problemas y operaciones aritméticas. Llevar esta forma de comunicación para enseñar y aprender matemáticas significa materialmente ampliar el radio de acción del p'urhepecha, en lo que consiste la esencia de la elaboración o extensión lingüística (Sprachausbau).

En cuanto al enfoque del Aprendizaje Integrado de Contenidos y Lenguas (AICL), mencionaríamos que estas clases son reflejo de los procesos de trabajo colectivo que han logrado articular, en distintos niveles, los contenidos de ambas lenguas con los de las diferentes asignaturas. El vínculo entre éstos nos permite hablar del carácter intercultural y bilingüe del currículo del proyecto escolar, pues apunta tanto a los procesos de desarrollo curricular y planificación, como a los procesos de enseñanza y aprendizaje en las aulas. Observamos también los diversos modos de apropiarse de los materiales por parte de los profesores, lo que nos ofrece múltiples perspectivas y temáticas sobre cómo se trabaja en este espacio escolar cuando se pone en práctica este enfoque. 


\section{PERSPECTIVAS DE LAS POLÍTICAS DE AUTOGESTIÓN Y LA CONSTRUCCIÓN DE PROYECTOS ESCOLARES DESDE ABAJO}

Frente a la triste realidad de nuestros Ministerios de Educación y sus oficinas subalternas para la atención a los indígenas en América Latina, surgen proyectos propios, auto-gestionados y sustentados en la fuerza cultural y política de los sectores más activos de los pueblos indígenas, las comunidades y sus organizaciones. Y frente a reformas educativas fracasadas, con sus paquetes de fraseología de macrohabilidades, competencias claves, aprendizajes esperados, parámetros curriculares, lenguas indígenas como lenguas adicionales, germinan proyectos educativos desde abajo, con distintos grados de autonomía de las burocracias educativas, que muestran su enorme potencial basado en las lenguas propias, los recursos culturales y las herramientas educativas de las comunidades de aprendizaje; que tienen legitimidad porque son productos propios, no paquetes cocinados en lo oscurito o maquilados en el extranjero y arrojados luego desde las torres de marfil de burocracias anquilosadas sobre las cabezas de los destinatarios.

Con todas las experiencias acumuladas, queda muy claro que ninguna mejoría de la calidad educativa en la educación púbica, y particularmente en la educación indígena, podrá lograrse sin una clara descentralización y una participación real de las comunidades educativas para que los nuevos diseños contengan contribuciones propias significativas, que adquieren legitimidad y que los actores educativos puedan apropiarse de ellos.

Los maestros y maestras del Proyecto T’arhexperakua demuestran día a día que es posible diseñar una política y una planificación educativa, lingüística y cultural desde las escuelas y sus comunidades. Evidencian en la práctica que es posible arraigar las lenguas y culturas originarias en espacios de prestigio, de movilizar y demostrar su extraordinaria vitalidad y funcionalidad para atender las necesidades educativas y las aspiraciones de identidad. Y todo esto ocurre en el micro-nivel de la práctica en las aulas donde se gesta la verdadera teoría, lejos de los debates metafísicos y especulativos, muchas veces sin base material, sobre la interculturalidad, colonialidad y epistemologías indígenas que abundan en ciertos círculos del neo-indigenismo educativo.

El trabajo paciente, coordinado e integrado de maestras y maestros indígenas en las escuelas de San Isidro y Uringuitiro demuestra en forma práctica que el p'urhepecha constituye un formidable instrumento para:

1. Recuperar y fortalecer valores, conceptualizaciones, taxonomías y modelos culturales que permiten la interpretación del mundo y la creación de una 
conciencia para la defensa de juchari ich'eri (nuestro territorio), como lo demuestra, no sin dificultades, la clase analizada sobre este tema.

2. Apropiarse de los conocimientos más abstractos y a la vez necesarios de la sociedad del conocimiento nacional y global, como hemos visto en la clase de matemáticas que moviliza la extraordinaria riqueza morfológica del p’urhepecha para abordar temas complejos como las fracciones.

3. Por último, el p’urhepecha como lengua de alfabetización contribuye también a una mejor adquisición del español como segunda lengua, proceso que se enriquece con las transferencias desde la primera lengua.

Docentes y alumnos constituyen así, junto con sus familias, una identidad étnica que tiene como centro neurálgico la lengua propia, pero no una lengua anquilosada que sólo mira hacia el pasado y representa una cultura folklorizada por la sociedad dominante. Es vigorosa, cambiante, dinámica y capaz de abarcar con eficiencia nuevos espacios de la vida moderna como lo son los dominios de prestigio en la educación. Sus actores constituyen un modelo y ejercen sin duda una presión positiva para preservar y reforzar la lengua propia. Si la revitalización de las lenguas indígenas constituye un objetivo deseable de las políticas públicas y para los movimientos indígenas, las presiones étnicas internas que conciben el dominio de la lengua como un componente relevante de la identidad y pertenencia étnicas, deberían considerarse como un factor coadyuvante muy importante para el éxito de la revitalización.

La política etnolingüística perseverante, que se refleja en el diseño y la ejecución de su proyecto escolar, le está dando frutos importantes a la colectividad docente en su empeño de proveerles a sus alumnos una experiencia menos traumática, más feliz y de mayor arraigo en una cultura étnica orgullosa de la que experimentaron ellos mismos en su infancia.

Para un maestro muy activo y experimentado, la participación en el proyecto escolar...

(...) ha sido una experiencia muy, muy buena, ¿no? que me ha dejado en lo personal, este... bastante conocimiento porque yo digo si el día de mañana o al siguiente ciclo escolar yo decido cambiarme de esta escuela pues lo que aquí he aprendido pues nadie, nadie me lo va a quitar, sino al contrario, ¿no?, va a ser para beneficio o a lo mejor, este... poder contagiar en algún otra, otro centro de trabajo este tipo de... o esta dinámica de trabajo, ¿no?

\section{REFERENCIAS}

ÁVILA, A. (2018). Lenguas indígenas y enseñanza de las matemáticas: la importancia de armonizar los términos. Revista colombiana de educación, 74, pp. 177-195. 
ALONSO, G.; ALONSO, P.; CANO, E; CORTÉS, S. (2004). La incomprensión de la lectura en español. Proyecto la lecto-escritura de la lengua p’urbepecha en el ámbito escolar, San Isidro-Uringuitiro.

AUER, P. (1999). From codeswitching via language mixing to fused lects: Toward a dynamic typology of bilingual speech. International Journal of Bilingualism, 3, 4, pp. 309-332.

COYLE, D. (2007). Content and language integrated learning: Towards a connected research agenda for CLIL pedagogies. International Journal of Bilingual Education and Bilingualism, 10, 5, pp. 543-562.

CUMMINS, J. (2000). Language, power and pedagogy. Clevedon: Multilingual Matters.

EMILSSON, E. (2010). Programa de español L2 en el marco de la educación bilingüe con enfoque comunicativo centrado en contenidos curriculares. Versión II. México: Universidad Autónoma Metropolitana-Iztapalapa.

FRANCIS, N. (2002). Modular perspectives on bilingualism. International Journal of Bilingual Education and Bilingualism, 5, pp. 141-161.

FRANCIS, N. (2012). Bilingual competence and bilingual proficiency in cbild development. Cambridge, MA: The MIT Press.

GAMIO, M. (1916/1992). Forjando Patria. México: Porrúa.

GONZÁLEZ APODACA, E. (2008). Los profesionistas indios en la educación intercultural. Etnicidad, intermediación y escuela en el territorio mixe. México: Universidad Autónoma MetropolitanaIztapalapa-Juan Pablos.

HALL HALEY, M. \& AUSTIN, T. Y. (2004) Content-based second language teacbing and learning. Boston: Pearson.

HAMEL, R. E. (2001). Políticas del lenguaje y educación indígena en México. Orientaciones culturales y estrategias pedagógicas en una época de globalización. En BEIN, R. \& BORN, J. (eds.) Políticas linguísticas - norma e identidad. Argentina: Universidad de Buenos Aires, pp. 143-170.

HAMEL, R. E., (2010). Hacia la construcción de un proyecto escolar de EIB. La experiencia p'urhepecha: investigación y acción colaborativa entre escuelas e investigadores, en VIII Congreso Latinoamericano de Educación Intercultural Bilingïe. Buenos Aires: Ministerio de Educación y UNICEF, pp. 113-135. 
HAMEL, R. E. (2016). Bilingual education for indigenous peoples in Mexico. In: García, O.; Lin, A. M. Y.; May S. (eds.). Bilingual and Multilingual Education. Vol 5 of the Encyclopaedia of Language and Education. New York: Springer. Vol. V, pp. 396-406.

HAMEL, R. E.; HECHT, A. C.; ERAPE BALTAZAR, A. E.; MARQUÉZ ESCAMILLA, H. B. (2018). Uandakurhintskua - biografías lingüísticas de docentes p’urhepechas. De la escolaridad traumática a la creación de un modelo educativo alternativo. CPU-e Revista de Investigación Educativa, 27, pp. 90-115.

HEATH, S. B. (1972). La política del lenguaje en México. De la colonia a la nación. México: SEP-INI.

INEE. (2008). La educación para poblaciones en contextos vulnerables. México: INEE.

INEE \& UNICEF (2016). Panorama Educativo de la Población Indígena. México: INEE.

KLOSS, H. (1978) Die Entwicklung nener germanischer Kultursprachen seit 1800. Düsseldorf: Schwann.

LÓPEZ, L. E. (ed.) (2009). Interculturalidad, educación y ciudadanía. La Paz: FUNPROEIB Andes \& Plural.

MENDONÇA, S. C. P. (2018). Crenças e atitudes linguísticas: estudo na aldeia guarani Tekoba Añetete em Diamante D'oeste/PR. Cascavel: Tese de qualificação.

MUÑNOZ CRUZ, H. (2009). Reflexividad sociolinguiística de bablantes de lenguas indígenas: concepciones y cambio sociocultural. Biblioteca Signos. México: Universidad Autónoma Metropolitana.

RICHARDS, J. C. \& RODGERS, T. S. (2001). Approaches and methods in language teaching. Cambridge: Cambridge University Press.

ROCKWELL, E. (2005). La apropiación, un proceso entre muchos que ocurren en ámbitos escolares. Memoria, conocimiento y utopía. Anuario de la Sociedad Mexicana de Historia de la Educación, 1, pp. 28-38.

SMOLICZ, J. (1981). Core values and cultural identity. Ethnic and racial studies, 4, 1, pp. 75-90.

SMOLICZ, J. (1994). Australia's language policies and minority rights: a core value perspective. In SKUTNABB-KANGAS, T. \& PHILLIPSON, R. (Eds.), Linguistic buman rights. Berlin \& Nueva York: Mouton de Gruyter, pp. 235-252.

Recebido: 22/10/2018

Aceito: 29/10/2018 